\title{
Landbird Trends in National Parks of the North Coast and Cascades Network, 2005-12
}

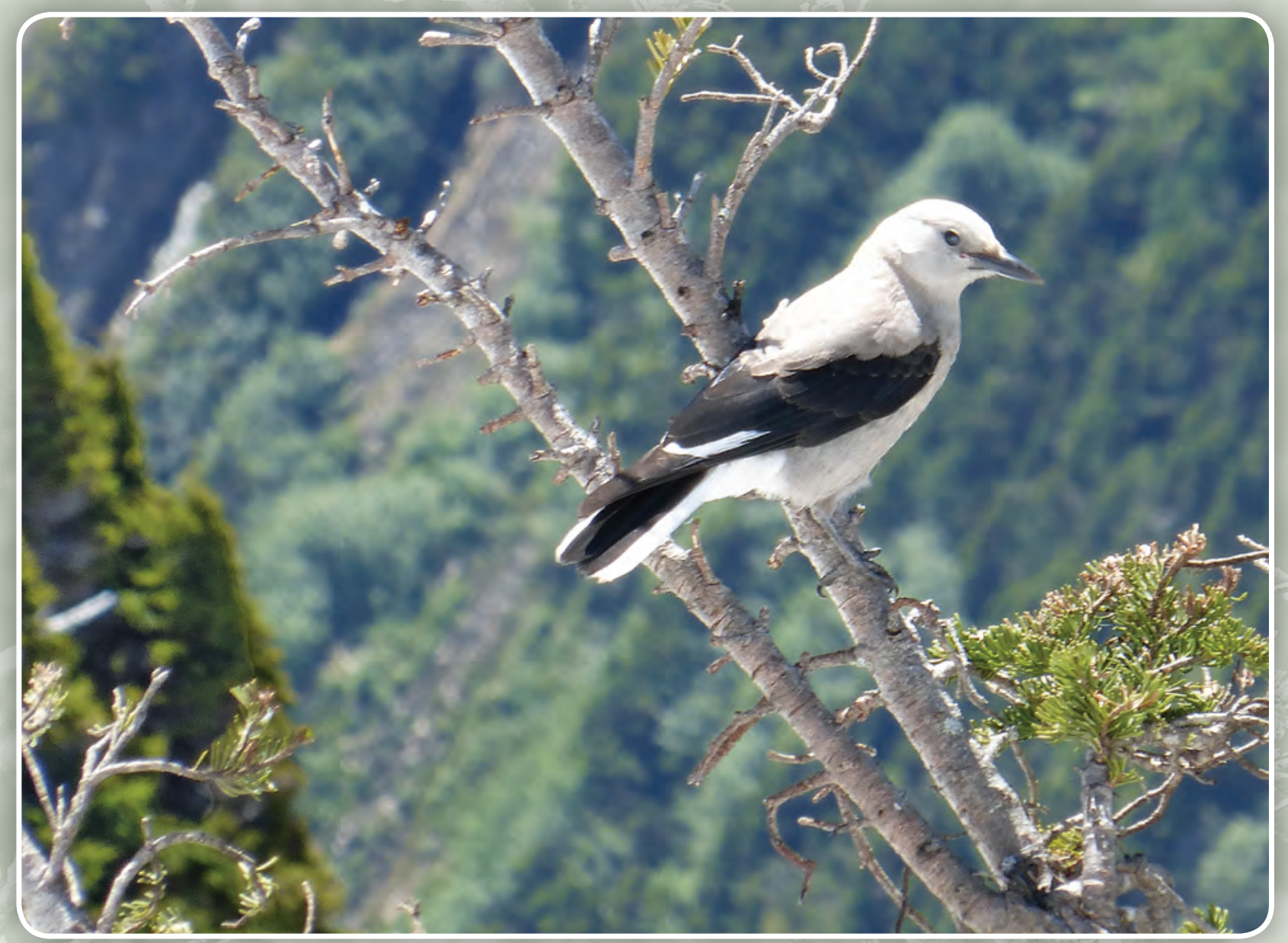

Open-File Report 2014-1202 
Cover: Clark's Nutcracker (Nucifraga columbiana) in North Cascades National Park. Photograph by Mandy Holmgren, The Institute for Bird Populations. 


\section{Landbird Trends in National Parks of the North Coast and Cascades Network, 2005-12}

By James F. Saracco, Amanda L. Holmgren, Robert L. Wilkerson, Rodney B.

Siegel, Robert C. Kuntz, II, Kurt J. Jenkins, Patricia J. Happe, John R. Boetsch, and Mark H. Huff

Prepared in cooperation with the National Park Service and

The Institute for Bird Populations

Open-File Report 2014-1202 


\title{
U.S. Department of the Interior SALLY JEWELL, Secretary
}

\section{U.S. Geological Survey \\ Suzette M. Kimball, Acting Director}

\author{
U.S. Geological Survey, Reston, Virginia: 2014
}

For more information on the USGS - the Federal source for science about the Earth, its natural and living resources, natural hazards, and the environment, visit http://www.usgs.gov or call 1-888-ASK-USGS.

For an overview of USGS information products, including maps, imagery, and publications, visit http://www.usgs.gov/pubprod

To order this and other USGS information products, visit http://store.usgs.gov

Any use of trade, firm, or product names is for descriptive purposes only and does not imply endorsement by the U.S. Government.

Although this information product, for the most part, is in the public domain, it also may contain copyrighted materials as noted in the text. Permission to reproduce copyrighted items must be secured from the copyright owner.

Suggested citation:

Saracco, J.F., Holmgren, A.L., Wilkerson, R.L., Siegel, R.B., Kuntz, R.C., II, Jenkins, K.J., Happe, P.J., Boetsch, J.R., and Huff, M.H., 2014, Landbird trends in national parks of the North Coast and Cascades Network, 2005-12: U.S. Geological Survey Open-File Report 2014-1202, 36 p., http://dx.doi.org/10.3133/ofr20141202.

ISSN 2331-1258 (online) 


\section{Contents}

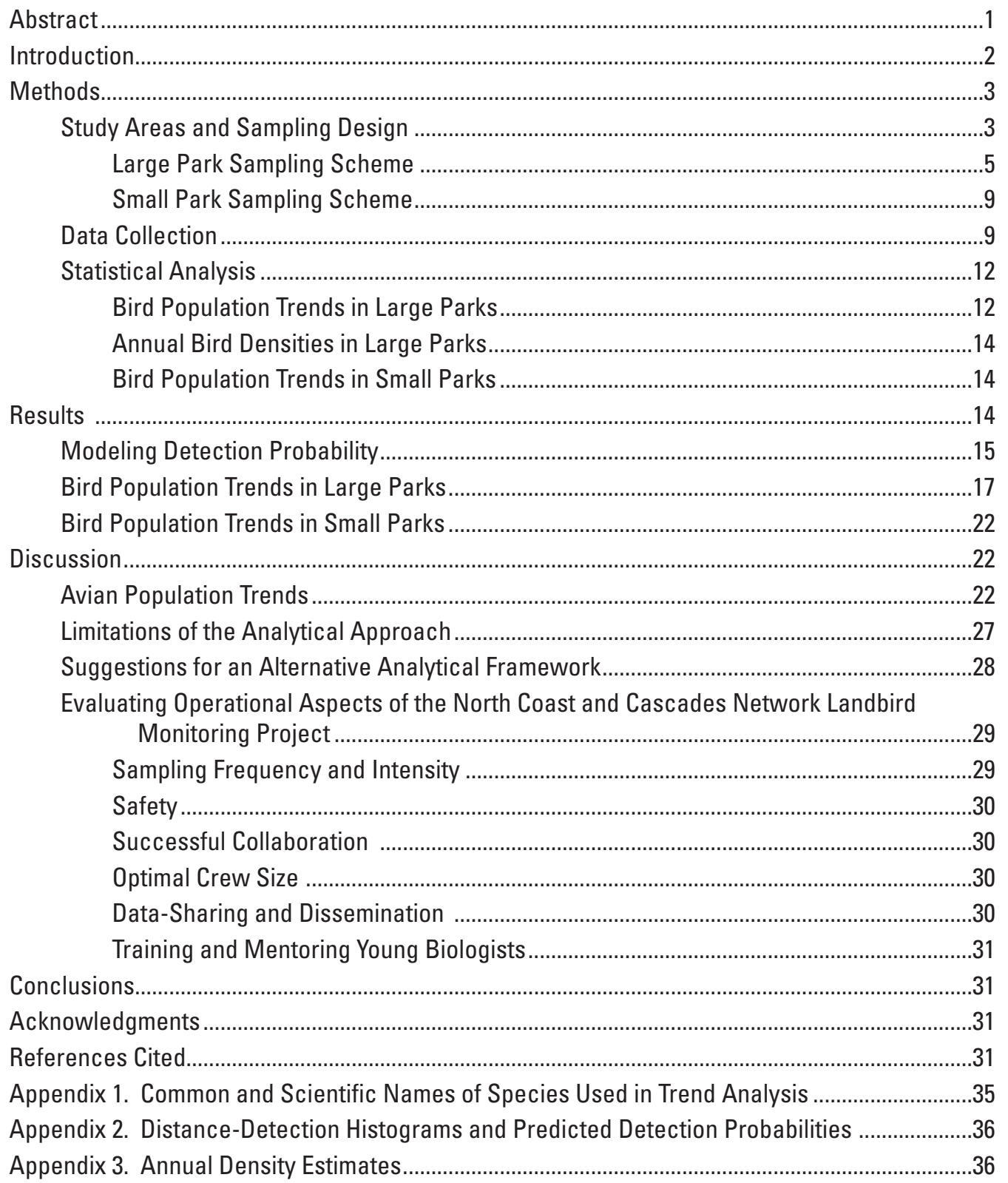




\section{Figures}

1. Map showing National Park Service units participating in the North Coast and Cascades Network Landbird Monitoring Project ...

2. Map showing approximate locations of transects established at Mount Rainier National Park, 2005-12...

3. Map showing approximate locations of transects established at North Cascades National Park Complex, 2005-12.

4. Map showing approximate locations of transects established at Olympic National Park, 2005-12.

5. Maps showing locations of point-count stations surveyed at Lewis and Clark National Historical Park, 2005-12

6. Maps showing locations of point count stations surveyed at San Juan Island National Historical Park, 2005-12

7. Graphs showing annual mean point density estimates ( \pm standard error) based on data from all points for two species with significantly decreasing trends at Mount Rainier National Park.

8. Graphs showing annual mean point density estimates ( \pm standard error) based on data from all points for seven species with significant trends at North Cascades National Park.

9. Graphs showing annual mean point density estimates ( \pm standard error) based on data from all points for eight species with significant trends at Olympic National Park.

10. Graphs showing annual mean point density estimates ( \pm standard error) based on data from all points for four species with significant trends across the three large wilderness parks of the North Coast and Cascades Network.

11. Graph showing annual snow meltout date (defined as ground surface albedo dropping below 30 percent) reported for individual snow telemetery ('SNOTEL') sites in each of the three large parks.

\section{Tables}

1. Number of potential transect starting points (sampling frame) spaced at 50-meter intervals along trails or roads at the three large North Coast and Cascades Network parks within each elevation stratum.

2. Numbers of transects sampled for each of the three large parks in each panel, elevation stratum, and year.

3. Summary of numbers of detections used in distance-detectability models, sample radius (radial distance containing 90 percent of observations), mean detection probabilities (from best model), and detail of models used for correcting survey data for imperfect detection.

4. Trends (annual proportional change) for large parks in the North Coast and Cascades Network, 2005-12.

5. Trends for Lewis and Clark National Historical Park sampled biennially ........................25

6. Trends for San Juan Island National Historical Park sampled biennially.........................26 


\section{Conversion Factors and Datums}

Conversion Factors

SI to Inch/Pound

\begin{tabular}{|c|c|c|}
\hline Multiply & By & To obtain \\
\hline meter (m) & 3.281 & foot $(\mathrm{ft})$ \\
\hline kilometer (km) & 0.6214 & mile (mi) \\
\hline
\end{tabular}

Datums

Vertical coordinate information is referenced to North American Vertical Datum of 1988 (NAVD 88).

Horizontal coordinate information is referenced to North American Datum of 1983 (NAD 83).

Elevation, as used in this report, refers to distance above the vertical datum. 



\title{
Landbird Trends in National Parks of the North Coast and Cascades Network, 2005-12
}

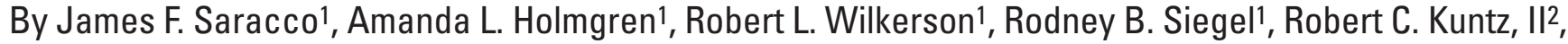 \\ Kurt J. Jenkins ${ }^{3}$, Patricia J. Happe ${ }^{4}$, John R. Boetsch5 ${ }^{5}$, and Mark H. Huff5
}

\section{Abstract}

National parks in the North Coast and Cascades Network (NCCN) can fulfill vital roles as refuges for bird species dependent on late-successional forest conditions and as reference sites for assessing the effects of land-use and land-cover changes on bird populations throughout the larger Pacific Northwest region. Additionally, long-term monitoring of landbirds throughout the NCCN provides information that can inform decisions about important management issues in the parks, including visitor impacts, fire management, and the effects of introduced species. In 2005, the NCCN began implementing a network-wide Landbird Monitoring Project as part of the NPS Inventory and Monitoring Program. In this report, we discuss 8-year trends (2005-12) of bird populations in the NCCN, based on a sampling framework of point counts established in three large wilderness parks (Mount Rainier, North Cascades, and Olympic National Parks), 7-year trends at Lewis and Clark National Historical Park (sampled in 2006, 2008, 2010, and 2012), and 5-year trends at San Juan Islands National Historical Park (sampled in 2007, 2009, and 2011). Our analysis encompasses a fairly short time span for this long-term monitoring program. The first 2 years of the time series (2005 and 2006) were implemented as part of a limited pilot study that included only a small subset of the transects. The subsequent 6 years (2007-12) represent just a single cycle through 5 years of alternating panels of transects in the large parks, with the first of five alternating panels revisited for the first time in 2012. Of 204 transects that comprise the six sampling panels in the large parks, only 68 (one-third) have thus been eligible for revisit surveys (34 during every year after 2005, and an additional 34 only in 2012) and can contribute to our current trend estimates. We therefore initiated the current analysis with a primary goal of testing

\footnotetext{
${ }^{1}$ The Institute for Bird Populations.

${ }^{2}$ North Cascades National Park Complex.

${ }^{3}$ U.S. Geological Survey, Forest and Rangeland Ecosystem Science Center.

${ }^{4}$ National Park Service, Olympic National Park.

${ }^{5}$ National Park Service, North Coast and Cascades Network.
}

our analytical procedures rather than detecting trends that might be strong enough to drive conservation or management decisions in the parks or elsewhere. We expect that aggregated trend detection results may change substantially over the next several years, as the number of transects with revisit histories triples and the spatial dispersion of transects contributing to trend estimates also improves greatly. In the meantime, caution should be exercised in interpreting the importance of trends, as individual years can have very large influences on the direction and magnitude of trends in a time series of such limited duration (and limited numbers of repeat visits at the small parks). Nevertheless, we estimated trends for 43 species at Mount Rainier National Park, 53 species at North Cascades National Park Complex, and 41 species at Olympic National Park. Of 137 park-species combinations (including combinedpark analyses), we found 16 significant decreases (12 percent) and five significant increases (4 percent).

We identify several limitations of the current analytical framework for trend assessment but suggest that the overall sampling design is strong and amenable to analysis by more recently developed model-based methods. These could provide a more flexible framework for examining trends and other population parameters of interest, as well as testing hypotheses that relate the distribution and abundance of species to environmental covariates. A model-based approach would allow for modeling various components of the detection process and analyzing observations (detection process), population state (occupancy, population size, density), and change (trend, local extinction and colonization rates turnover) simultaneously. Finally, we also evaluate operational aspects of NCCN Landbird Monitoring Project, and conclude that our robust, multi-party partnership is successfully implementing the project as it was envisioned. 


\section{Introduction}

National parks in the North Coast and Cascades Network (NCCN) can fulfill vital roles as both refuges for bird species dependent on late-successional forest conditions and as reference sites for assessing the effects of land-use and land-cover changes on bird populations throughout the larger Pacific Northwest region (Silsbee and Peterson, 1991; Siegel and others, 2012). These changes may result from regional processes such as land conversion and forest management, or from broader-scale phenomena such as global climate change. Monitoring population trends at 'control' sites in national parks is especially important because the parks are among the few sites in the United States where population trends resulting from large-scale regional or global change patterns are relatively unaffected by local changes in land use (Simons and others, 1999).

In 2007, the NCCN launched its Landbird Monitoring Project, which monitors population trends of dozens of bird species in three large wilderness parks and two smaller, historical parks that also comprise significant natural resources. Birds were selected for monitoring as they represent one of the key vital signs of all signs of park ecosystem health. Vital signs are selected physical, chemical, and biological elements and processes of park ecosystems that represent the overall condition of the park resources, known or hypothesized effects of stressors, or elements that have important human values (http://science.nature.nps.gov/im/ monitor/docs/Monitoring_Brochure.pdf). Birds were selected not only out of concern for their population status, but also for the great interest they hold for the public, their distribution across nearly all portions of all parks, and the potential for monitoring dozens of species simultaneously across multiple parks with a single, integrated protocol.

From the outset, the NCCN Landbird Monitoring Project has served as a model for other resource monitoring efforts within the National Park Service (NPS). The NCCN landbird protocol (Siegel and others, 2007) was the first protocol approved in the NCCN and one of the first approved avian monitoring protocols in the NPS. A very similar protocol, patterned explicitly after the NCCN protocol, was later adopted and implemented by the Sierra Nevada Network (SIEN) (Siegel and others, 2010).Data from the North American Breeding Bird Survey (BBS) suggest that many landbird populations in Pacific Northwest coniferous forests have decreased in recent decades (Andelman and Stock, 1994a, 1994b; Sharp, 1996; Saab and Rich, 1997; Altman, 2000, 2005; Sauer and others, 2012). Sauer and others (2012) report that 35 percent of 164 species in the Northern Pacific Rainforest Bird Conservation Region significantly decreased between 1966 and 2011, while only 13 percent of the species significantly increased in the region over the same time period.

As climate change continues and likely accelerates in the coming decades, many bird species in the region are likely to be affected by changes in weather patterns, habitat structure and distribution, and phenology of food availability. Recent studies from elsewhere in the montane west suggest that birds dependent on high-elevation habitats may be particularly likely to be jeopardized by climate change (Gardali and others, 2012; Siegel and others, 2014), but also that effects may be complicated across montane regions, with some species undergoing range expansions and population increases and other species experiencing range contractions, population decreased, and possibly local extirpation. The NCCN Landbird Monitoring Project is poised to detect and describe many of these changes in bird populations within the parks.

In addition to climate change, threats to bird populations breeding in Pacific Northwest coniferous forests include habitat loss and fragmentation, as well as altered forest structure resulting from varied forest management practices. Large tracts of low-elevation coniferous forest have been lost to residential and agricultural development since World War II (Bolsinger and Waddell, 1993). Landscapes managed for timber production are now often dominated by early- and mid-successional forest (Bunnell and others, 1997), may be highly fragmented, and can exhibit structural characteristics 
that can alter avian community structure and diminish bird diversity (Meslow and Wight, 1975; Hagar and others, 1995; Bunnell and others, 1997; Altman, 2005; Linden and others, 2012; Linden and Roloff, 2013; Yegorova and others, 2013). Pacific Northwest landbirds breeding in habitats other than coniferous forests face substantial threats as well. Species that breed in the subalpine and alpine zones, for example, may face ecological changes resulting from visitor impacts, among other issues. The NCCN protects and manages substantial highelevation bird habitat; Oregon-Washington Partners in Flight identified monitoring birds in high-elevation areas throughout the Pacific Northwest as an important need and suggested that the NPS should be a key player in this monitoring (Altman and Bart, 2001). Additional threats face migratory landbirds that breed in the Pacific Northwest. For example, land-use changes or climate change on the wintering grounds and along migration routes may influence overwinter survival of migratory species.

The primary and secondary objectives of the NCCN Landbird Monitoring Project, respectively, are to (1) detect trends in the density of as many landbird species (including passerines, near passerines, and galliformes) as possible throughout accessible areas of five NCCN parks during the breeding season, and (2) to track changes in the breeding season distribution of landbird species in each park throughout accessible areas of the three large wilderness parks. In this report, we discuss 8-year trends (2005-12) of bird populations in the NCCN, based on a sampling framework of point counts established in three large wilderness parks (Mount Rainier, North Cascades, and Olympic National Parks), 7-year trends at Lewis and Clark National Historical Park (sampled in 2006, 2008, 2010, and 2012), and 5-year trends at San Juan Islands National Historical Park (sampled in 2007, 2009, and 2011). The secondary goal of the NCCN Landbird Monitoring Project, tracking changes in the breeding season distribution of landbird species, will be pursued in the coming years after a longer temporal span of data have been collected and new analytical methods are developed. An additional objective of this report is to evaluate the effectiveness of the Landbird Monitoring Project and identify any improvements that may be implemented.

\section{Methods}

\section{Study Areas and Sampling Design}

Bird surveys were conducted in three large wilderness parks (North Cascades [NOCA], Olympic [OLYM], and Mount Rainier [MORA] National Parks); and in two small parks (Lewis and Clark National Historical Park [LEWI] and San Juan Island National Historical Park [SAJH]; fig. 1). The three large parks span elevations from sea level to 4,400 m above sea level and contain large tracts of late-successional, coniferous forest on the Olympic Peninsula and the western slope of the Cascades Range, as well as areas dominated by subalpine and alpine plant communities. NOCA also includes substantial tracts of coniferous forest typical of the eastern side of the Cascades, which hosts a somewhat distinct avifauna (Altman, 2000). SAJH, in the rainshadow of the Olympic Mountains, includes small but important examples of coastal prairie and Garry Oak woodlands, plant communities that are fairly rare in western Washington (Atkinson and Sharpe, 1985), and hosts distinct bird communities (Lewis and Sharpe, 1987; Siegel and others, 2009e). LEWI includes lowland wetlands as well as coastal and upland forests, and extends our project's area of inference substantially southward. Because the three large parks of the NCCN are vastly larger and pose different logistical constraints than the smaller NCCN parks, we implemented two separate sampling schemes; one for the three large wilderness parks (MORA, OLYM, NOCA) and one for the two smaller parks (SAJH, LEWI). 


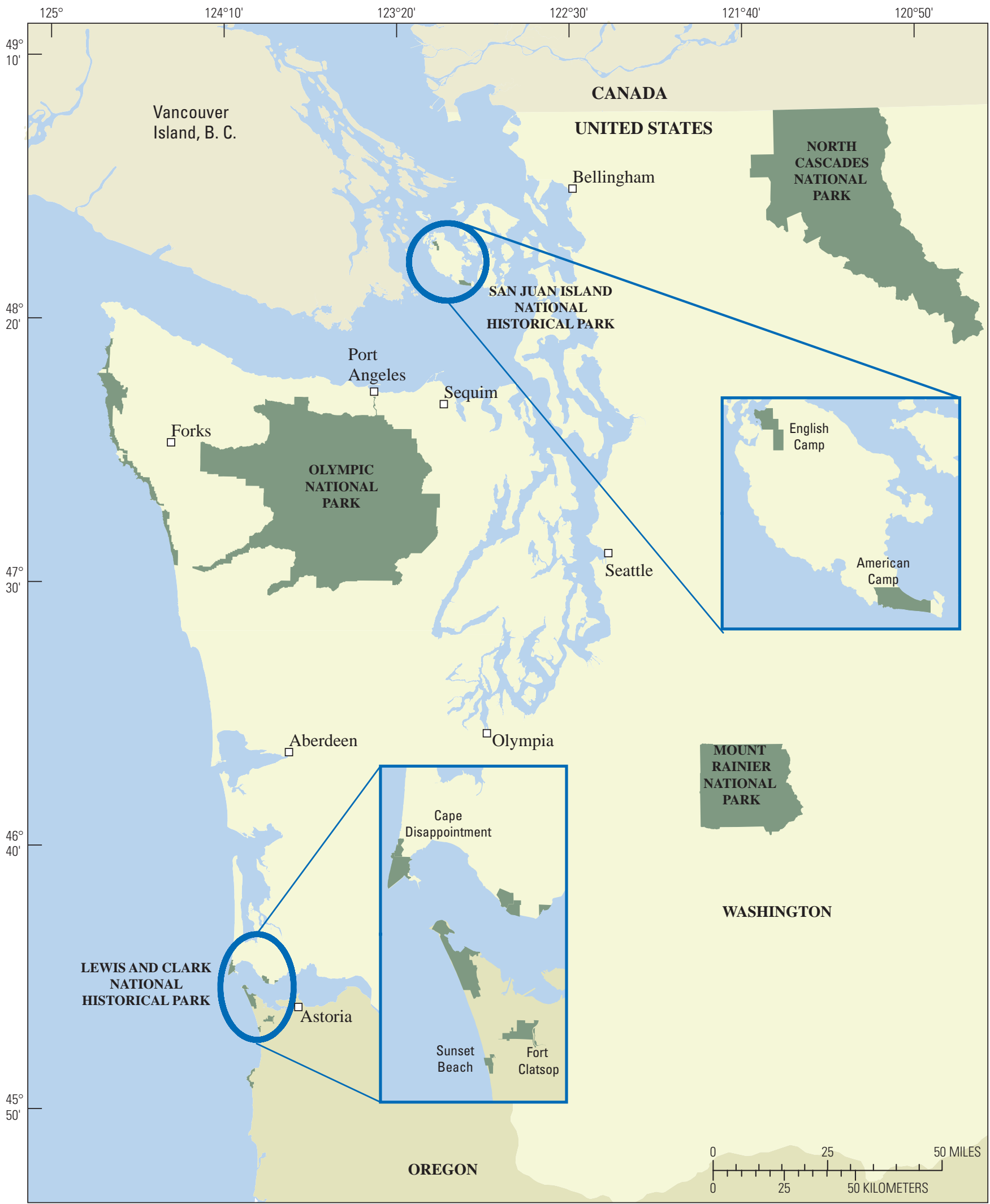

Base map modified from National Park Service and US Geological Survey digital data, various scales. Coordinate Reference System: UTM Zone 10N, horizontal datum is North American Datum of 1983.

Figure 1. National Park Service units participating in the North Coast and Cascades Network Landbird Monitoring Project. 


\section{Large Park Sampling Scheme}

Early efforts to conduct geographically extensive bird surveys in NCCN parks (Jenkins and others, 2000; Siegel and others, 2009a, 2009c, 2009d, and 2009e) explored logistical and safety challenges in monitoring bird populations across the NCCN's three large wilderness parks. Although we desired a sampling scheme that would approximate park-wide inference as closely as possible, some compromises had to be made because of constraints stemming from the parks' large size, limited road access, rugged terrain, frequent inclement weather, and associated safety considerations. At the three large parks, sampling for the long-term Landbird Monitoring Project was conducted along point-count transects using methods described in detail by Siegel and others (2007). For safety and logistical reasons, all transects emanated from a park trail (the vast majority of transects) or road (a small portion of the transects) (figs. 2-4). Although we limited the sampling frame (and inferences) to a buffer of approximately $1 \mathrm{~km}$ in either direction along trails and roads, a substantial portion of wilderness in each of the three large parks was available for sampling within that buffer. The $1-\mathrm{km}$ buffer included 57 percent of the total land area at MORA, 31 percent at NOCA, and 39 percent at OLYM. Although the areas within the buffers could not perfectly represent the mix of habitats and environmental conditions across the entire landscapes of the parks, in all cases they included a broad diversity of habitats such that any bias introduced by this sampling design was deemed acceptably small relative to the safety and logistic benefits (Siegel and others, 2007).

The sampling frame of potential transects started from points spaced every $50 \mathrm{~m}$ along maintained trails and roads in each park and extending perpendicularly away from the access routes. For transects emanating along trails, if off-trail travel was not possible, the transect was established directly on the trail. We used Geographic Information Systems (GIS) data to screen and eliminate potential starting points that were unusable because they were along roads in steep areas where off-road sampling would not be possible, paralleled shorelines of large lakes or reservoirs where one-half the points would be in open water or were located along roads that were too wide and/or busy with traffic to allow for safe or meaningful sampling. We used GIS data to classify the remaining transect starting points into low-, mid-, or high-elevation strata. For NOCA and OLYM, we defined low-elevation stratum as all potential transects with starting points less than $650 \mathrm{~m}$ above sea level; mid-elevation stratum as all potential transects with starting points between and including 650 and $1,350 \mathrm{~m}$ above sea level; and high-elevation stratum as all potential transects with starting points greater than $1,350 \mathrm{~m}$ above sea level. For MORA only, we adjusted the boundary between the low- and mid-elevation strata to $800 \mathrm{~m}$, as virtually none of the park is less than $650 \mathrm{~m}$ above sea level, but otherwise defined the elevation strata in the same manner as for the other parks. The number of potential transect starting points (that is, the sampling frame or total available population units) for each park and elevation is presented in table 1.
Transects were selected based on an augmented serially alternating panel design (Urquhart and others, 1998). Based on this design we established one set, or panel, of transects to be surveyed annually (that is, the annual panel) and 5 sets of transects that will be revisited on a 5-year return interval (that is, the alternating panels). Each year we sampled the annual panel of transects and one of the five alternating panels. This design allowed for sampling a relatively large overall number of transects over the 5-year sampling cycle (providing better representation of diverse habitats and regions in each park), while providing substantial year-to-year continuity in the dataset by sampling transects in the annual panel every year (Breidt and Fuller, 1999; Urquhart and Kincaid, 1999; McDonald, 2003). Spatially dispersed, random sampling locations were selected as transect starting points using the Generalized Random-Tessellation Stratified (GRTS) sampling method (Stevens and Olsen, 1999, 2003, 2004) with reverse hierarchical ordering. The GRTS sampling method is wellsuited for large-scale environmental monitoring programs, in part because it generally creates a spatially balanced sample while allowing for additional sample units to be added or subtracted without compromising the spatial balance (Stevens and Olsen, 2003, 2004). In NOCA and OLYM, we selected a total of 72 transects consisting of 12 transects in each of the six panels. Each panel was populated with four transects sampled from each elevation stratum. In MORA, because of the relatively small fraction of the park lying within the lowelevation stratum boundaries, we only sampled 60 transects total, consisting of 10 transects in each panel, with two, four, and four transects in low-, mid-, and high-elevation strata, respectively.

Each year, the sampling scheme included surveys of the annual panel as well as one of the alternating panels. During the first 2 years of protocol development (2005-06), we surveyed only the annual panel (Siegel and others, 2006, 2009b). Thereafter, we attempted to complete 24 transects at NOCA and OLYM and 20 at MORA each year, with sample effort in each park allocated evenly between the annual panel and one of the five alternating panels.

From selected starting points on trails or roads, transects extended perpendicularly in both directions with point count stations spaced $200 \mathrm{~m}$ apart. Observers followed a set of pre-defined decision rules for redirecting transects when cliffs, impassable streams, or other obstacles were encountered (Siegel and others, 2007). Where off-trail travel was impossible, transects were established on trails rather than along routes perpendicular to them. Depending on difficulty of travel and terrain, the number of points sampled along each transect ranged from 8 to 25 . Because there was annual variability in the number of points sampled per transect, we based the trend analysis on the minimum number of points in which surveys were completed each year (generally the first 8-12 points of any transect). Avian detections made from points that were not sampled every year contributed to tabulations of species observed, but were not used in trend analysis. 


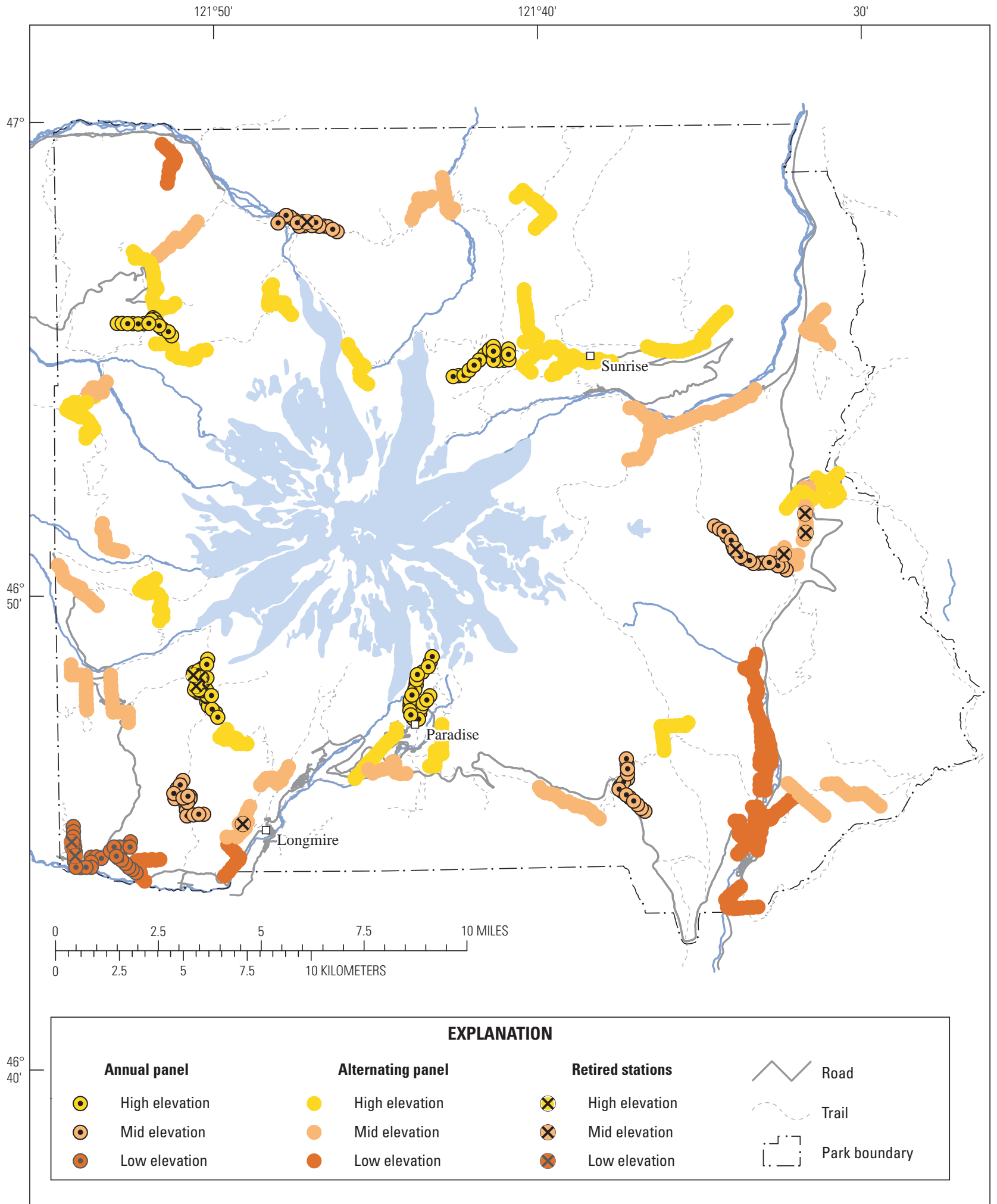

Base map modified from National Park Service and US Geological Survey digital data, various scales. Coordinate Reference System: UTM Zone 10N, horizontal datum is North American Datum of 1983.

Figure 2. Approximate locations of transects established at Mount Rainier National Park, 2005-12. Each circular symbol represents a point-count station along a transect. Low-elevation stratum-all potential transects with starting points less than $800 \mathrm{~m}$ above sea level. Mid-elevation stratum —all potential transects with starting points between and including 800 and 1,350 m above sea level. High-elevation stratum—all potential transects with starting points greater than 1,350 $\mathrm{m}$ above sea level. 


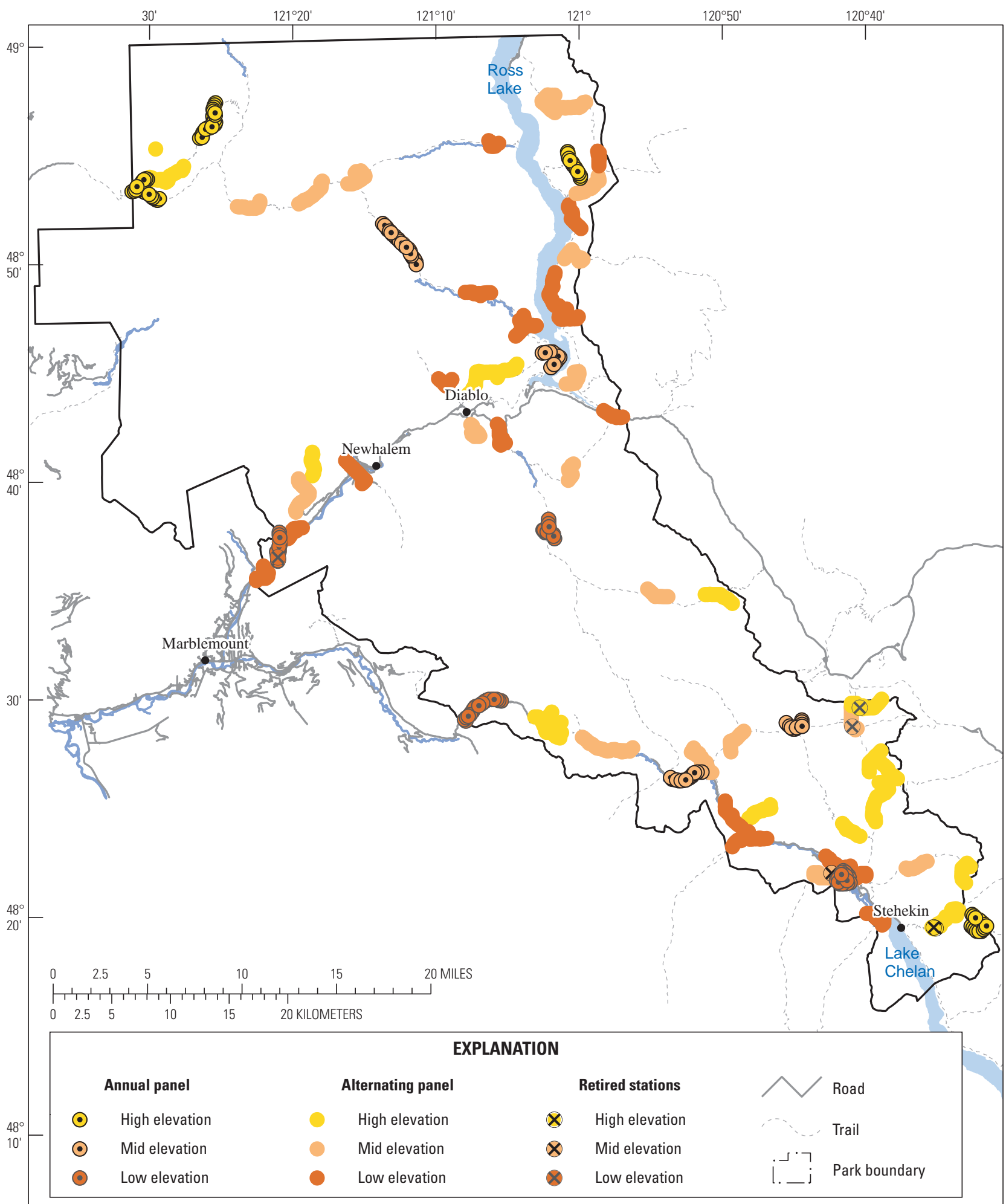

Base map modified from National Park Service and US Geological Survey digital data, various scales. Coordinate Reference System: UTM Zone 10N

horizontal datum is North American Datum of 1983.

Figure 3. Approximate locations of transects established at North Cascades National Park Complex, 2005-12. Each circular symbol represents a point-count station along a transect. Low-elevation stratum—all potential transects with starting points less than $800 \mathrm{~m}$ above sea level. Mid-elevation stratum—all potential transects with starting points between and including 800 and $1,350 \mathrm{~m}$ above sea level. High-elevation stratum —all potential transects with starting points greater than 1,350 $\mathrm{m}$ above sea level. 


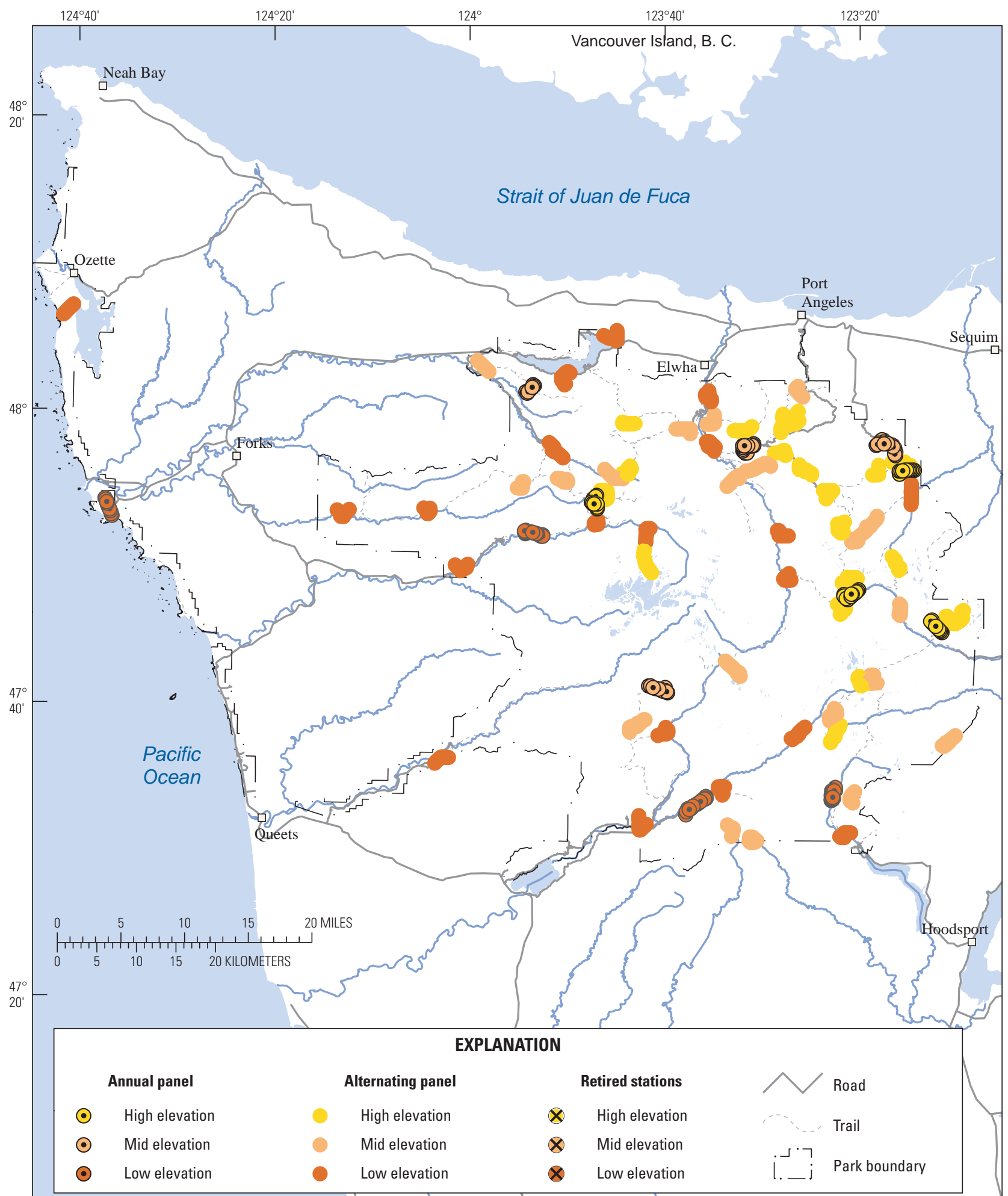

Base map modified from National Park Service and US Geological Survey digital data, various scales. Coordinate Reference System: UTM Zone 10N, horizontal datum is North American Datum of 1983.

Figure 4. Approximate locations of transects established at Olympic National Park, 2005-12. Each circular symbol represents a point-count station along a transect. Low-elevation stratum-all potential transects with starting points less than $800 \mathrm{~m}$ above sea level. Mid-elevation stratum—all potential transects with starting points between and including 800 and 1,350 m above sea level. High-elevation stratum—all potential transects with starting points greater than 1,350 $\mathrm{m}$ above sea level. 
Table 1. Number of potential transect starting points (sampling frame) spaced at 50-meter intervals along trails or roads at the three large North Coast and Cascades Network parks within each elevation stratum.

[E levation stratum: For NOCA and OLYM, low-elevation strata are defined as all potential transects with starting points less than $650 \mathrm{~m}$ above sea level; mid-elevation strata are defined as all potential transects with starting points between and including 650 and $1,350 \mathrm{~m}$ above sea level; high-elevation strata are defined as all potential transects with starting points greater than 1,350 $\mathrm{m}$ above sea level. For MORA only, the boundary between the low- and mid-elevation strata was adjusted to $800 \mathrm{~m}$, but otherwise defined as the elevation strata in the same manner as for the other parks]

\begin{tabular}{lccc}
\hline & \multicolumn{3}{c}{ Elevation stratum } \\
\cline { 2 - 4 } & Low & Mid & High \\
\hline Mount Rainier National Park (MORA) & 1,094 & 3,754 & 4,837 \\
North Cascades National Park (NOCA) & 4,000 & 5,112 & 2,079 \\
Olympic National Park (OLYM) & 9,771 & 6,872 & 3,972 \\
\hline
\end{tabular}

\section{Small Park Sampling Scheme}

Because travel and logistics did not pose significant problems in the two smaller parks, we sampled bird populations from points distributed as a systematic grid (with a random starting point) covering each park area in its entirety (figs. 5-6). Grid points were $350 \mathrm{~m}$ apart, yielding 54 point count stations at SAJH (including 38 points at American Camp and 16 points at English Camp) and 71 point count stations at LEWI (including 29 points at Fort Clatsop, 5 points at Sunset Beach, and 37 points at Cape Disappointment). Nine additional points were initially established and surveyed at Cape Disappointment, but were later retired because of logistical concerns (fig. 5). Points at each small park were sampled every second year, alternating between the two parks each year. We sampled at LEWI during 4 years $(2006,2008$, 2010, and 2012) and at SAJH during 3 years $(2007,2009$, and 2011).

\section{Data Collection}

Once we began implementing the full sampling scheme in 2007 (after the 2005 and 2006 pilot years), crew size ranged from six to eight crew members each year, including one crew leader. Prior to collecting data each year, all crew members participated in a 3 week training session led by personnel from The Institute for Bird Populations and the National Park Service. This training included identification of all species by sight and sound, as well as the accurate estimation of distances of singing birds from the observers. Before collecting data, crew members were required to pass an examination testing their ability to identify park birds by sight and sound.

Data collection was timed to coincide with the peak of singing for most species. To avoid counting large numbers of still-migrating birds, the crew began collecting data no earlier than May 23 at NOCA and OLYM and no earlier than June 1 at MORA. The two small parks (LEWI and SAJH) were sampled during the last week of May or the first week of June. At all three of the large parks, crew members began sampling at low elevations early in the season and gradually moved upslope as the season progressed. All surveys were completed by July 31 .

In concordance with other NPS bird monitoring protocols (Coonan and others, 2001; Peitz and others, 2002; Siegel and Wilkerson, 2005), we surveyed landbirds at points over a 5-minute period within two survey intervals ( $0-3$ and 3-5 minutes). Beginning in 2011, a third 2-minute sampling interval was added to facilitate application of time-of-detection methods for accounting for imperfect detection (Alldredge and others, 2007a). However, we do not include those data in the analysis presented here (to maintain a consistent protocol over the entire study). We estimated distances to all birds (or groups of birds) encountered (Reynolds and others, 1980; Fancy, 1997; Nelson and Fancy, 1999; Rosenstock and others, 2002), except for a small number of individuals which were classified as 'flyovers' without any real connection to the habitat below them, to enable estimation and modeling of detection probability as a function of distance, and subsequent estimation of point-level avian densities (Buckland and others, 2001, 2004). 

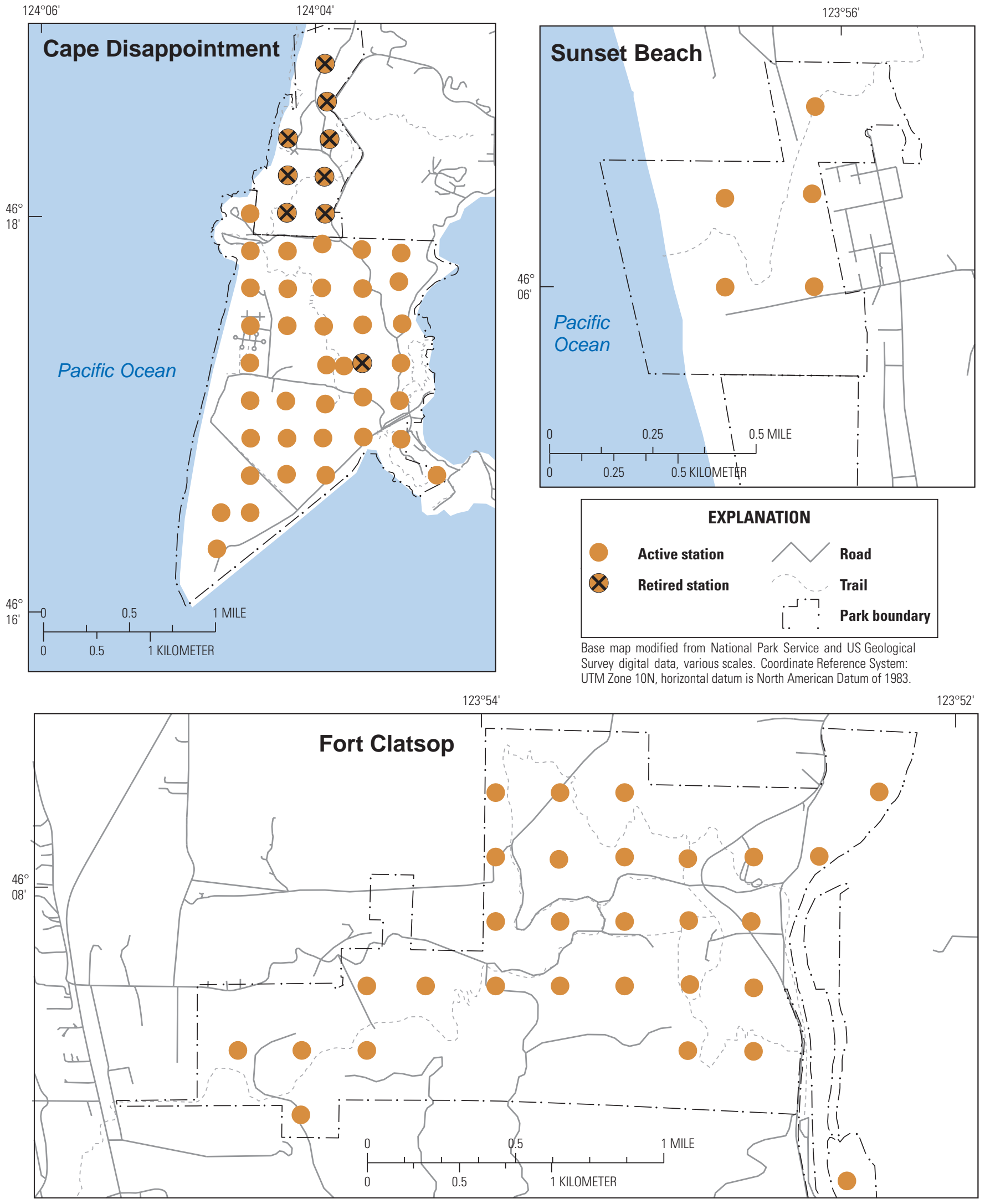

Figure 5. Locations of point-count stations surveyed at Lewis and Clark National Historical Park, 2005-12. 



Figure 6. Locations of point count stations surveyed at San Juan Island National Historical Park, 2005-12. 


\section{Statistical Analysis}

We wrote scripts in the statistical program $\mathrm{R}(\mathrm{R}$ Development Core Team, 2012) to estimate distancedetectability functions and population trends following general guidelines provided in Siegel and others (2007). Detectability functions were estimated using the R package 'Distance' (Miller, 2012). For each species, we truncated 10 percent of observations that represented the largest detection distances to avoid complicating distance-detection functions, which would otherwise need to accommodate long tails in the data (Buckland and others, 2001; Thomas and others, 2010). We estimated distance-detection functions for species with greater than or equal to 75 detections (to meet minimum sample sizes requirements suggested by Buckland and others, 2001). Common and scientific names of all species analyzed are listed in appendix 1.

For each species, we considered up to 12 distancedetectability models (not all models were estimable for all species). These included conventional distance sampling (CDS) models, as well as models that allowed detection functions to vary by observer, by broad habitat class (sparse versus dense-canopied), or by observer and habitat class (additive model). For both the CDS and covariate models, we considered three key-function adjustment-term combinations suggested by Thomas and others (2010): half-normal key with cosine adjustment, half-normal key with Hermite adjustment, and hazard-rate key with simple polynomial adjustment. We compared models using Akaike's Information Criterion (AIC) and AIC model weights (Burnham and Anderson, 2002).

For some species-covariate model combinations (primarily for species with smaller sample sizes and models including observer effects), we had difficulty in estimating all model parameters (suggesting over-fitting), such that the mean detection probabilities were estimated with very low precision. Whenever coefficients of variation (CVs) on mean detection probability exceeded 100 percent, we excluded these models from further consideration (even if those models had lowest AIC). In addition, model convergence was not achieved for all species-model combinations. Based on the detection function from the best-performing model (lowest AIC with reasonable precision on mean detection probability estimates), we corrected point-level counts for variation in detection probability and then divided corrected counts by the actual sampling area at points (defined as a circle with radius equal to the longest detection distance after truncating the longest 10 percent of observations) to provide point density estimates for use in trend analyses.

\section{Bird Population Trends in Large Parks}

For the three large parks, we estimated 8-year trends using BirdTrend (Ver. 1.2; August 2013), a trend-analysis program developed by the TerraStat Consulting Group (see appendix 4 in Siegel and others, 2007) for use in the statistical software package R (R Development Core Team, 2012). BirdTrend evaluates linear trend in log+1-transformed mean point densities along each transect. In this report, we include the annual panel (sampled in all years, 2005-12) and data from one alternating panel (the only panel for which more than 1 year of sampling had been completed at the time of our analysis) sampled in 2007 and 2012.

The trend analysis method implemented in BirdTrend was closely linked to the availability of potential sampling points (that is, the sampling frame) in each of three elevation strata (see section, "Methods-Study Areas and Sampling DesignLarge Parks Sampling Scheme, for detail). Trend estimation followed a hierarchical process, whereby first, for each species and park, slopes of the linear regressions of the $\log +1$ transformed densities (adjusted through distance sampling to account for imperfect detection probability) on year (as a continuous covariate) were estimated for each of $i=1, \ldots, n$ transects. By log-transforming the response variable, we made the density data less right-skewed (to better meet assumption of normally-distributed residuals), and the regression coefficient was easily interpretable as the approximate annual proportional change in density (Sokal and Rohlf, 1995). We did not include a particular transect in the analysis for a given species if the species was never detected on that transect; thus, $n$ varied by species. The individual transect-level slopes, denoted here as $y_{i}$, were then averaged at the level of each of $j=1, \ldots s=3$ elevation strata (including transects from both the annual and alternating panel):

$$
\bar{y}_{j}=\frac{\sum_{i=1}^{n_{j}} y_{i j}}{n_{j}}
$$

Note that we diverge from the annotation of appendix 4 in Siegel and others (2007) here by indexing first at the transect (i), then at the strata ( $j$ ) levels. Additionally, we do not include summation over variance groups (see below) in equation 1 to emphasize that variance group assignments do not enter into estimation of the mean stratum-level slope. Mean stratumlevel slopes were then combined to provide an estimate of the mean park-level trend:

$$
\overline{\bar{y}}=\frac{1}{N} \sum_{j=1}^{s} N_{j} \bar{y}_{j}
$$

where

$$
\begin{gathered}
N \quad \begin{array}{c}
\text { is the total available population units } \\
\text { (sampling frame), and }
\end{array} \\
N_{j} \quad \begin{array}{l}
\text { is the number of available population units } \\
\text { within each of the } j \text { strata (table 1). }
\end{array}
\end{gathered}
$$

Thus, the park-level trend was weighted by the availability of potential sampling points in each elevation stratum. 
Estimation of variances of stratum-level and park-level mean trends required assigning each transect to a variance group (Siegel and others, 2007, appendix 6). Within each elevation stratum, we assumed that transects with similar numbers of sampled years had similar trend slope variance. Thus, for each stratum, we initially assigned all annual panel transects to a single variance group. Most (79 percent) transects in the annual panel were surveyed in all 8 years (the fewest number of years sampled for a transect in the annual panel was one transect at OLYM that was sampled in only 5 years). We initially assigned transects of the alternating panel for each elevation stratum to a second variance group. However, for many species, small sample sizes in some panel-stratum combinations precluded trend and trend-variance estimation with the initial variance group assignment, requiring combining variance groups or removing transects from the analysis for BirdTrend to provide estimates of trend variance and statistical tests of trend significance. Specifically, when a species was detected on only a single transect in a panel-elevation-stratum combination, it was assigned to the variance group of the other panel in the same elevation stratum. Although BirdTrend will provide mean trend and variance estimates if transects are reassigned to a variance group from another elevation stratum (because variance groups do not enter in to mean stratum- or park-level trend estimation; equations 1 and 2), tests of the statistical significance of trends were not possible in these cases in the current BirdTrend version. Thus, if a species was only encountered on a single transect in a particular elevation stratum, that transect was removed from the analysis.

Variances of stratum-level mean trends were estimated as:

$$
\operatorname{Var}\left(\bar{y}_{j}\right)=\frac{1}{n_{j}^{2}} \sum_{k=1}^{V_{j}} m_{j k} s_{j k}^{2}
$$

where

$$
\begin{array}{cl}
V_{j} & \text { is the number of variance groups in stratum } j, \\
m_{j k} & \text { is the number of transects in stratum } j \text { and } \\
& \text { variance group } k, \text { and } \\
s_{j k}^{2} & \text { is the sample variance of slopes for variance } \\
& \text { group } k \text { in elevation stratum. } j .
\end{array}
$$

The right side of equation 3 reduces to $s_{j}^{2} / n_{j}$ whenever there is only a single variance group in elevation stratum $j$ (because $m_{j k}=n_{j}$ in that case). Park-level variances were estimated as:

$$
\operatorname{Var}(\bar{y})=\frac{1}{N^{2}} \sum_{j=1}^{s} N_{j}^{2} \operatorname{Var}\left(\bar{y}_{j}\right) .
$$

Statistical significance of park-level trends was assessed by comparing the park-level mean trend (equation 2) divided by the standard error of this mean (that is, square-root of equation 4) to the t-distribution with degrees of freedom estimated using Satterthwaite's formula (Satterthwaite, 1946):

$$
\frac{\left(\sum_{j=1}^{s} \frac{N_{j}\left(N_{j}-n_{j}\right)}{n_{j}} \times s_{j}^{2}\right)^{2}}{\sum_{j=1}^{s}\left(\frac{N_{j}^{2}\left(N_{j}-n_{j}\right)^{2}}{n_{j}^{2}\left(n_{j}-1\right)} \times s_{j}^{4}\right)}
$$

If only a single transect occurs in an elevation stratum, the denominator of equation 5 cannot be calculated, and thus the degrees of freedom for the t-test cannot be estimated (hence, the need to remove the "orphaned" transects from the analysis as described above).

For species that occurred on more than one transect in each of the three elevation strata at all three large parks, we also estimated a mean combined-park trend:

$$
\overline{\bar{Y}}=\frac{1}{T} \sum_{p=1}^{3} T_{p} \bar{y}_{p}
$$

where

$$
\begin{aligned}
& T \quad \text { is the total number of non-zero transects } \\
& T_{p} \quad \text { is the number of transects in park } p \text {, and } \\
& \bar{y}_{p} \quad \text { is the average trend for park } p \text { (based on }
\end{aligned}
$$

The variance of this combined-park trend estimate was estimated as:

$$
\operatorname{Var}(\stackrel{\bar{Y}}{)})=\frac{1}{T^{2}} \sum_{p=1}^{3} T_{p}^{2} \operatorname{Var}\left(\bar{y}_{p}\right) .
$$

Statistical significance was assessed by dividing the combinedpark mean trend (eq. 6) by the standard error of this mean (that is, square-root of eq. 7) and comparing to the t-distribution with degrees of freedom estimated using Satterthwaite's formula as computed in a manner analogous to what was done for the park-level trends (eq. 5). For all trend analyses, we used two-tailed tests with $\alpha=0.10$. We adopted this relatively liberal alpha level to increase the likelihood of early detection of real trends that might be of particular interest to managers and the lack of a substantial cost associated with false trend detection (Field and others, 2004). 


\section{Annual Bird Densities in Large Parks}

In addition to estimating trends, we calculated mean transect-level annual densities (adjusted for imperfect detectability) for each park using the program BirdTrendAnnualDensity (ver. 1.1), based on data from all transects and all points sampled (regardless of whether detections were recorded or not). Specifically, for each of the 8 years, we estimated the park-level density as:

$$
\overline{\bar{D}}=\frac{1}{N} \sum_{j=1}^{s} N_{j} \bar{D}_{j}
$$

where

$\bar{D}_{j} \quad$ is the mean point-level density for each transect; calculated in the same way as for trend in equation 1 , with the exception that all transects, not just those with detections, were used in the analysis.

The variance of equation 8 was calculated in a manner analogous to equation 3 .

\section{Bird Population Trends in Small Parks}

For the two small parks, we estimated trends using a linear regression of the mean $(\log +1)$-transformed point-level annual density on year. Trend was assessed based on the regression coefficient for the year effect and its associated t-statistic and $P$-value. As for the large-park analyses, we assigned significance based on a two-tailed test with $\alpha=0.10$.

Table 2. Numbers of transects sampled for each of the three large parks in each panel, elevation stratum, and year.

[National Park: MORA, Mount Rainier; NOCA, North Cascades; OLYM, Olympic]

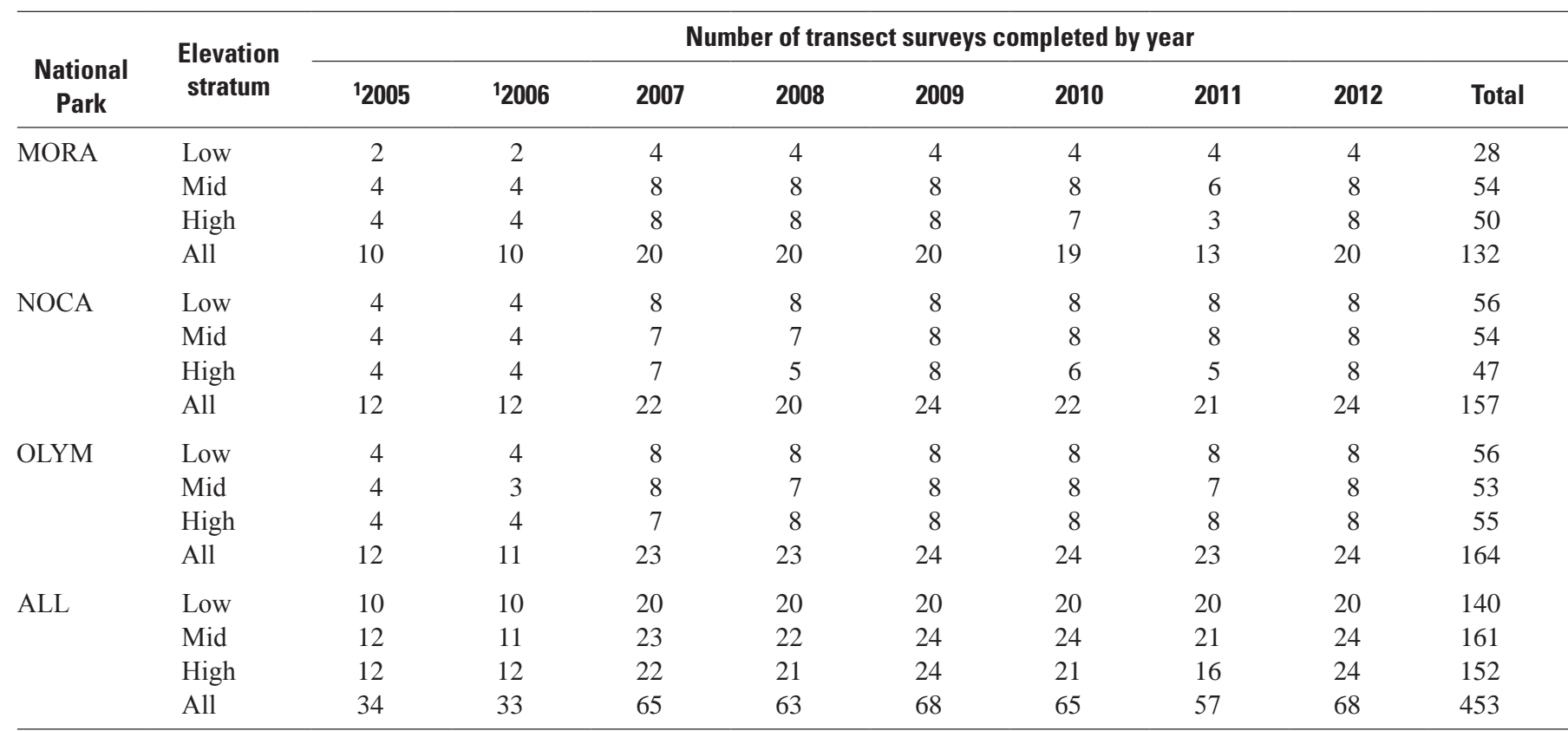

${ }^{1}$ Only the annual panel transects were surveyed in 2005 and 2006, during the protocol development phase of the project. 


\section{Modeling Detection Probability}

We provide a summary of distance-detectability functions used in correcting count data collected on bird surveys in table 3 . The sample radius (defined here as the distance containing 90 percent of observations) averaged $127 \mathrm{~m}$ and, as expected, was highly variable among species, ranging from a low of $29 \mathrm{~m}$ (Rufous Hummingbird) to a high of $340 \mathrm{~m}$ (Common Raven). Mean detection probability for the 61 species at a point during the 5 -minute count was 0.368 . Only about one-half of the species, most with greater than 500 detections, could support more complicated distancedetectability modeling (that is, those with observer effects included as covariates). On average, only about 7 of the 12 models could be fit with reasonable precision to be considered as candidates for correcting counts for imperfect detection. We provide histograms of distance-detection data and predicted detection probabilities based on best (lowest AIC) models with reasonable precision on mean detection probability estimates ( $\mathrm{SE}<$ mean) in appendix 2 (online supplementary material). A feature common to many species was fewer-than-expected observations close to the observer (in two-dimensional distance), suggesting that birds either avoided or were flushed by (for example, on approach) observers, or that observers had difficulty in correctly assigning distances to nearby birds that may have been high overhead in tall trees or on steep slopes.

Table 3. Summary of numbers of detections used in distance-detectability models, sample radius (radial distance containing 90 percent of observations), mean detection probabilities (from best model), and detail of models used for correcting survey data for imperfect detection.

[Up to 12 models for 61 species with $\geq 75$ detections (after removing the most distant 10 percent of detections) were considered. Species names are presented in standard taxonomic order (Chesser and others, 2013)]

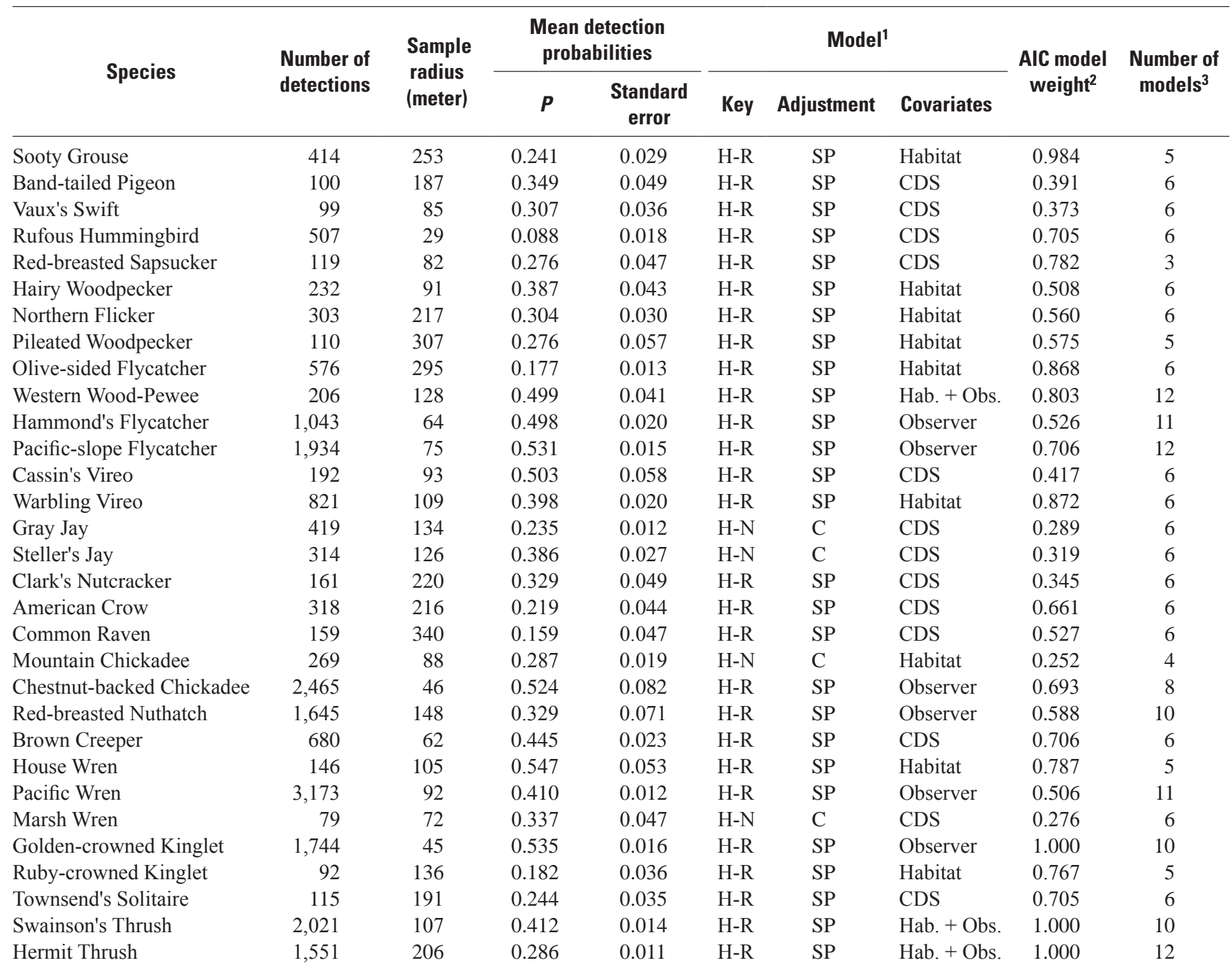


Table 3. Summary of numbers of detections used in distance-detectability models, sample radius (radial distance containing 90 percent of observations), mean detection probabilities (from best model), and detail of models used for correcting survey data for imperfect detection.-Continued

[Up to 12 models for 61 species with $\geq 75$ detections (after removing the most distant 10 percent of detections) were considered. Species names are presented in standard taxonomic order (Chesser and others, 2013)]

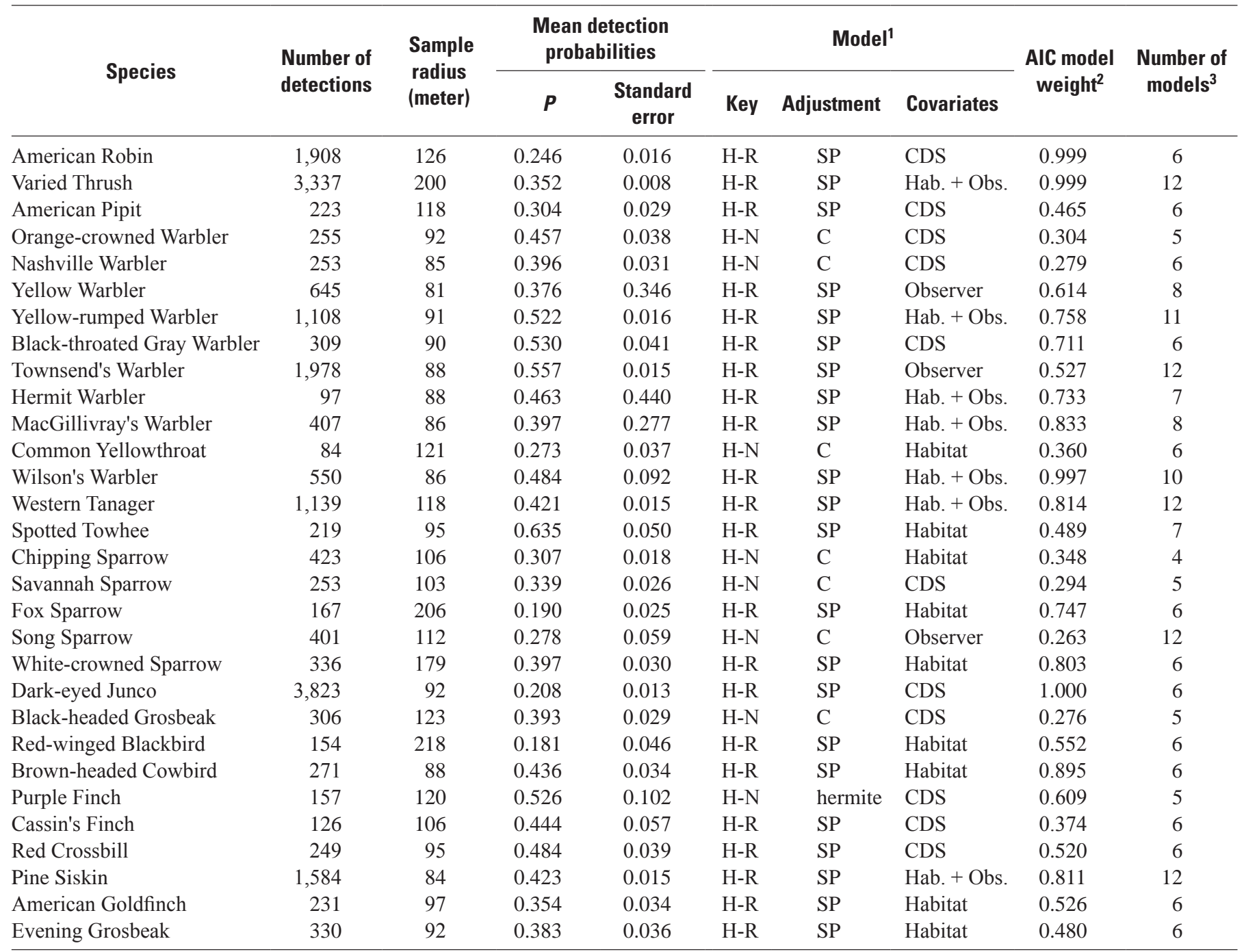

\footnotetext{
${ }^{1}$ Model used for the distance-detectability function. Key = key function (half-normal $[\mathrm{H}-\mathrm{N}]$ or hazard rate [H-R]); Adjustment = adjustment terms (cosine $[\mathrm{C}]$, hermite $[\mathrm{H}]$, or simple polynomial[SP]); Covariate = covariates included in mean function of model, where CDS = conventional distance sampling (no covariates), habitat $=$ dense or sparse, and Observer $=$ observer identity

${ }^{2}$ Akaike Information Criterion (AIC) model weight for model used for the distance-detectability function.

${ }^{3}$ Number of models included in candidate model set (maximum $=12$; model set culled when precision on mean detection probability low [SE $>$ mean]).
} 


\section{Bird Population Trends in Large Parks}

We estimated trends for 43 species at MORA, 53 species at NOCA, and 41 species at OLYM (table 4). Of 137 parkspecies combinations, 12 significantly $(P<0.10)$ decreased $(9$ percent) and 5 (4 percent) significantly increased. Annual density estimates for each species in each park are provided in appendix 3 (online supplementary material).

At MORA, two of 43 species (5 percent) significantly decreased and 0 species significantly increased (table 4). On average from 2005 to 2012, Pacific Wren decreased by about 1.6 percent per year and Golden-crowned Kinglet decreased by about 5.6 percent per year. Mean transect-level densities, however, suggested high annual variability and heterogeneous trends across the study period. For both species, abundance increased from 2005 to 2007, sharply decreased in 2008, recovered somewhat in 2009 (although not to peak pre-2008 levels), and tended to decrease thereafter (fig. 7).

At NOCA, five of 53 species ( 9 percent; table 3 ) significantly decreased. Significant decreases ranged from 1.4 to 2.2 percent per year for Red-breasted Sapsucker, Swainson's Thrush, and Hermit Thrush to greater than 3 percent per year for Golden-crowned Kinglet and Dark-eyed Junco. Two species (4 percent of those analyzed) significantly increased at NOCA — Gray Jay (increase of 1 percent per year) and Western Tanager (increase of 1.6 percent per year). Annual variation in densities for species with significant trends was high (fig. 8). As at MORA, species with decreasing trends actually tended to increase across the first 3 years of the study and decreased thereafter.
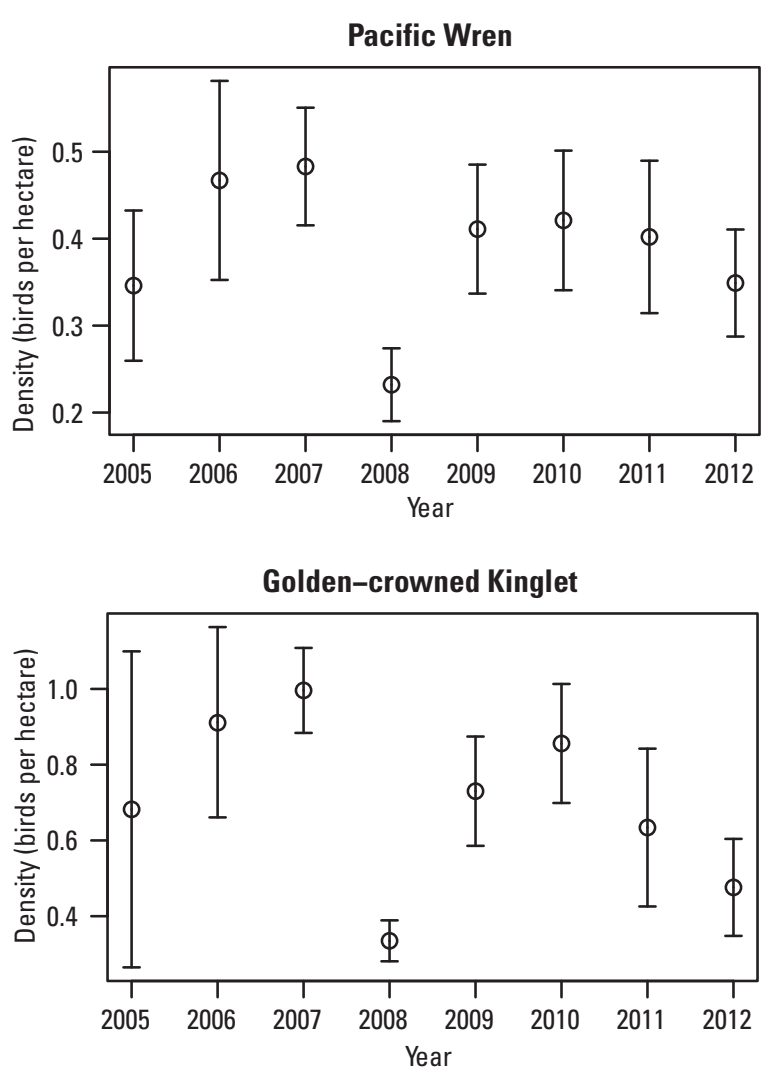

Figure 7. Annual mean point density estimates ( \pm standard error) based on data from all points (that is, not just from transects with detections) for two species with significantly decreasing trends at Mount Rainier National Park.

Table 4. Trends (annual proportional change) for large parks in the North Coast and Cascades Network, $2005-12$.

[Trends were estimated using the computer program BirdTrend (ver. 1.2), which bases park-level trends on mean transect-level trends, while accounting for unequal sampling among three elevation strata (see section, Methods-Statistical Analysis_Bird Population Trends in Large Parks, for detail). Species names are presented in standard taxonomic order (Chesser and others, 2013). Significant slopes $(\mathrm{P}<0.10)$ are shown in bold]

\begin{tabular}{|c|c|c|c|c|c|c|c|}
\hline Species & Park & $\begin{array}{c}\text { Number of } \\
\text { non-zero } \\
\text { transects }\end{array}$ & $\begin{array}{l}\text { Mean } \\
\text { of } \\
\text { slope }\end{array}$ & $\begin{array}{c}\text { Variance } \\
\text { of } \\
\text { slope }\end{array}$ & df & t-stat & $\begin{array}{c}\text { 2-tailed } \\
p \text {-value }\end{array}$ \\
\hline \multirow{2}{*}{ Sooty Grouse } & NOCA & 19 & -0.00070 & 0.00000 & 15.48 & -0.4753 & 0.6412 \\
\hline & OLYM & 20 & -0.00025 & 0.00000 & 15.18 & -0.2307 & 0.8207 \\
\hline Band-tailed Pigeon & OLYM & 10 & -0.00217 & 0.00000 & 3.02 & -4.4860 & 0.0203 \\
\hline \multirow{2}{*}{ Vaux's Swift } & NOCA & 9 & 0.00633 & 0.00029 & 3.35 & 0.3710 & 0.7329 \\
\hline & OLYM & 7 & -0.02402 & 0.00009 & 3.94 & -2.4947 & 0.0681 \\
\hline \multirow[t]{3}{*}{ Rufous Hummingbird } & MORA & 10 & -0.08639 & 0.00414 & 7.71 & -1.3422 & 0.2177 \\
\hline & NOCA & 16 & -0.05031 & 0.00276 & 8.21 & -0.9575 & 0.3657 \\
\hline & OLYM & 14 & -0.08106 & 0.00181 & 3.90 & -1.9043 & 0.1314 \\
\hline \multirow{2}{*}{ Hairy Woodpecker } & OLYM & 13 & -0.00969 & 0.00001 & 7.48 & -2.5109 & 0.0383 \\
\hline & Combined & 39 & -0.00316 & 0.00001 & 29.60 & -0.9215 & 0.3642 \\
\hline
\end{tabular}


Table 4. Trends (annual proportional change) for large parks in the North Coast and Cascades Network, 2005-12.-Continued

[Trends were estimated using the computer program BirdTrend (ver. 1.2), which bases park-level trends on mean transect-level trends, while accounting for unequal sampling among three elevation strata (see section, Methods-Statistical Analysis-Bird Population Trends in Large Parks, for detail). Species names are presented in standard taxonomic order (Chesser and others, 2013). Significant slopes $(\mathrm{P}<0.10)$ are shown in bold]

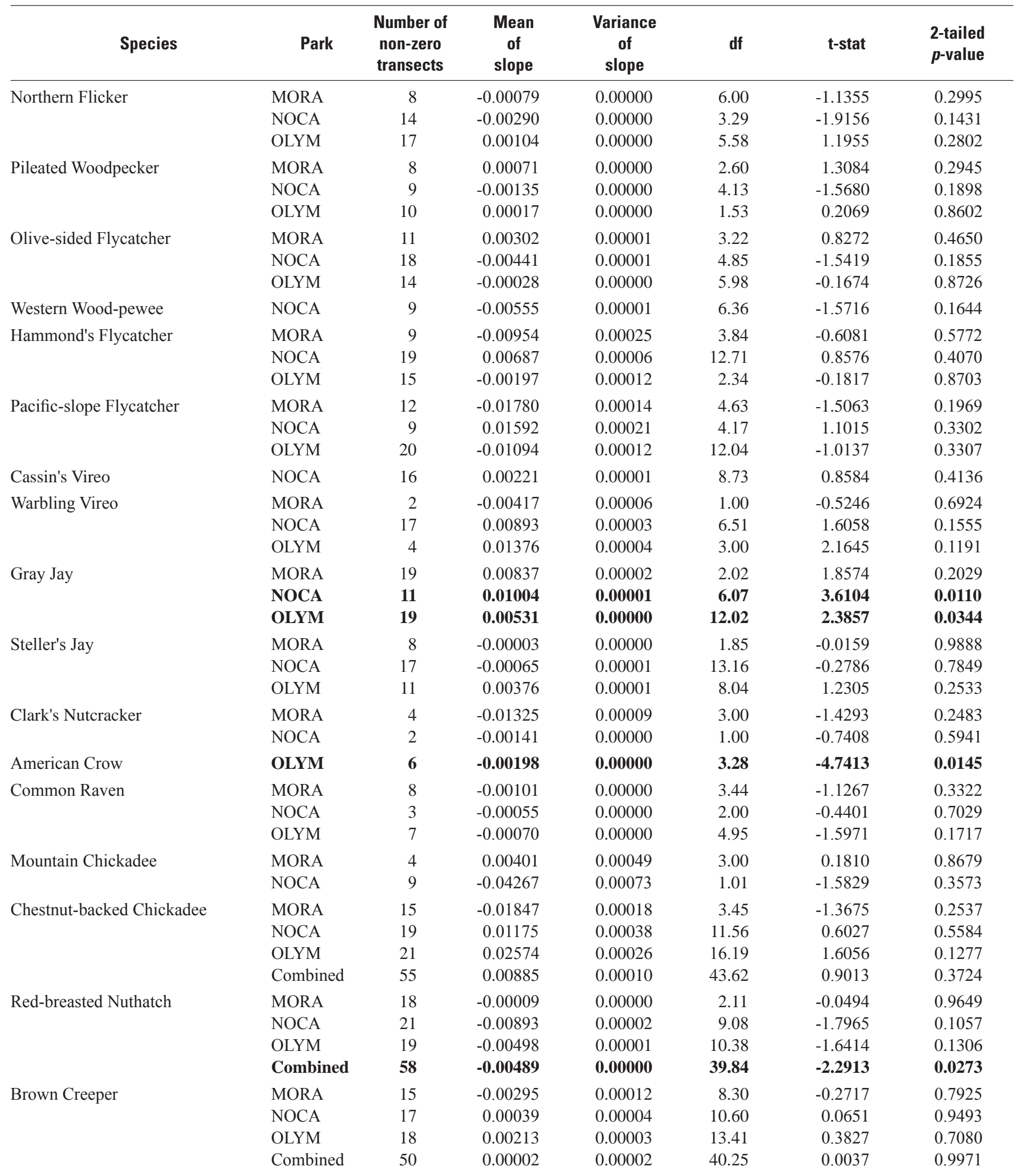


Table 4. Trends (annual proportional change) for large parks in the North Coast and Cascades Network, 2005-12.—Continued

[Trends were estimated using the computer program BirdTrend (ver. 1.2), which bases park-level trends on mean transect-level trends, while accounting for unequal sampling among three elevation strata (see section, Methods - Statistical Analysis-Bird Population Trends in Large Parks, for detail). Species names are presented in standard taxonomic order (Chesser and others, 2013). Significant slopes $(\mathrm{P}<0.10)$ are shown in bold]

\begin{tabular}{|c|c|c|c|c|c|c|c|}
\hline Species & Park & $\begin{array}{c}\text { Number of } \\
\text { non-zero } \\
\text { transects }\end{array}$ & $\begin{array}{l}\text { Mean } \\
\text { of } \\
\text { slope }\end{array}$ & $\begin{array}{c}\text { Variance } \\
\text { of } \\
\text { slope }\end{array}$ & df & t-stat & $\begin{array}{c}\text { 2-tailed } \\
p \text {-value }\end{array}$ \\
\hline \multirow{3}{*}{ Pacific Wren } & NOCA & 20 & 0.00588 & 0.00007 & 11.16 & 0.6833 & 0.5084 \\
\hline & OLYM & 23 & -0.02380 & 0.00019 & 9.94 & -1.7422 & 0.1123 \\
\hline & Combined & 61 & -0.01185 & 0.00004 & 28.97 & -1.9756 & 0.0578 \\
\hline \multirow{2}{*}{ Golden-crowned Kinglet } & OLYM & 22 & -0.02147 & 0.00041 & 15.41 & -1.0659 & 0.3029 \\
\hline & Combined & 61 & -0.03540 & 0.00009 & 33.18 & -3.6601 & 0.0009 \\
\hline \multirow[t]{2}{*}{ Ruby-crowned Kinglet } & NOCA & 3 & -0.02617 & 0.00023 & 2.00 & -1.7209 & 0.2274 \\
\hline & OLYM & 3 & -0.01946 & 0.00005 & 2.00 & -2.7589 & 0.1101 \\
\hline Townsend's Solitaire & MORA & 3 & -0.01151 & 0.00003 & 2.00 & -2.0872 & 0.1721 \\
\hline \multirow{2}{*}{ Swainson's Thrush } & NOCA & 19 & -0.02207 & 0.00006 & 12.07 & -2.9748 & 0.0115 \\
\hline & OLYM & 7 & -0.00877 & 0.00006 & 6.00 & -1.1711 & 0.2859 \\
\hline \multirow[t]{3}{*}{ Hermit Thrush } & MORA & 17 & -0.01042 & 0.00002 & 1.02 & -2.3628 & 0.2502 \\
\hline & NOCA & 14 & -0.01532 & 0.00002 & 4.16 & -3.7189 & 0.0191 \\
\hline & OLYM & 15 & -0.00709 & 0.00002 & 12.04 & -1.5108 & 0.1566 \\
\hline \multirow[t]{4}{*}{ American Robin } & MORA & 16 & -0.01388 & 0.00005 & 6.29 & -1.9152 & 0.1017 \\
\hline & NOCA & 22 & -0.00887 & 0.00010 & 12.35 & -0.8807 & 0.3953 \\
\hline & OLYM & 21 & 0.01281 & 0.00001 & 15.02 & 3.5292 & 0.0030 \\
\hline & Combined & 59 & -0.00251 & 0.00002 & 51.53 & -0.5671 & 0.5731 \\
\hline \multirow[t]{2}{*}{ Varied Thrush } & MORA & 20 & 0.00476 & 0.00003 & 13.85 & 0.8944 & 0.3864 \\
\hline & NOCA & 21 & -0.00179 & 0.00001 & 15.42 & -0.5335 & 0.6013 \\
\hline Nashville Warbler & NOCA & 12 & 0.01122 & 0.00003 & 3.06 & 2.2225 & 0.1110 \\
\hline \multirow[t]{2}{*}{ Yellow Warbler } & MORA & 2 & -0.01460 & 0.00003 & 1.00 & -2.5387 & 0.2389 \\
\hline & NOCA & 14 & -0.00797 & 0.00008 & 8.19 & -0.8840 & 0.4019 \\
\hline \multirow[t]{3}{*}{ Yellow-rumped Warbler } & MORA & 9 & -0.00527 & 0.00006 & 1.29 & -0.6848 & 0.5957 \\
\hline & NOCA & 21 & 0.00985 & 0.00005 & 15.97 & 1.3488 & 0.1962 \\
\hline & OLYM & 5 & 0.00013 & 0.00012 & 2.00 & 0.0114 & 0.9919 \\
\hline \multirow[t]{3}{*}{ Black-throated Gray Warbler } & MORA & 3 & -0.01911 & 0.00048 & 2.00 & -0.8682 & 0.4768 \\
\hline & NOCA & 12 & 0.00794 & 0.00007 & 8.81 & 0.9761 & 0.3550 \\
\hline & OLYM & 4 & 0.01282 & 0.00013 & 3.00 & 1.1369 & 0.3382 \\
\hline \multirow[t]{4}{*}{ Townsend's Warbler } & MORA & 12 & -0.00531 & 0.00012 & 4.94 & -0.4759 & 0.6544 \\
\hline & NOCA & 21 & 0.00049 & 0.00011 & 11.16 & 0.0472 & 0.9632 \\
\hline & OLYM & 13 & 0.00493 & 0.00001 & 7.79 & 1.3571 & 0.2127 \\
\hline & Combined & 46 & 0.00023 & 0.00003 & 34.21 & 0.0412 & 0.9674 \\
\hline Hermit Warbler & MORA & 3 & -0.00445 & 0.00001 & 2.00 & -1.3732 & 0.3034 \\
\hline
\end{tabular}


Table 4. Trends (annual proportional change) for large parks in the North Coast and Cascades Network, 2005-12.-Continued

[Trends were estimated using the computer program BirdTrend (ver. 1.2), which bases park-level trends on mean transect-level trends, while accounting for unequal sampling among three elevation strata (see section, Methods - Statistical Analysis-Bird Population Trends in Large Parks, for detail). Species names are presented in standard taxonomic order (Chesser and others, 2013). Significant slopes $(\mathrm{P}<0.10)$ are shown in bold]

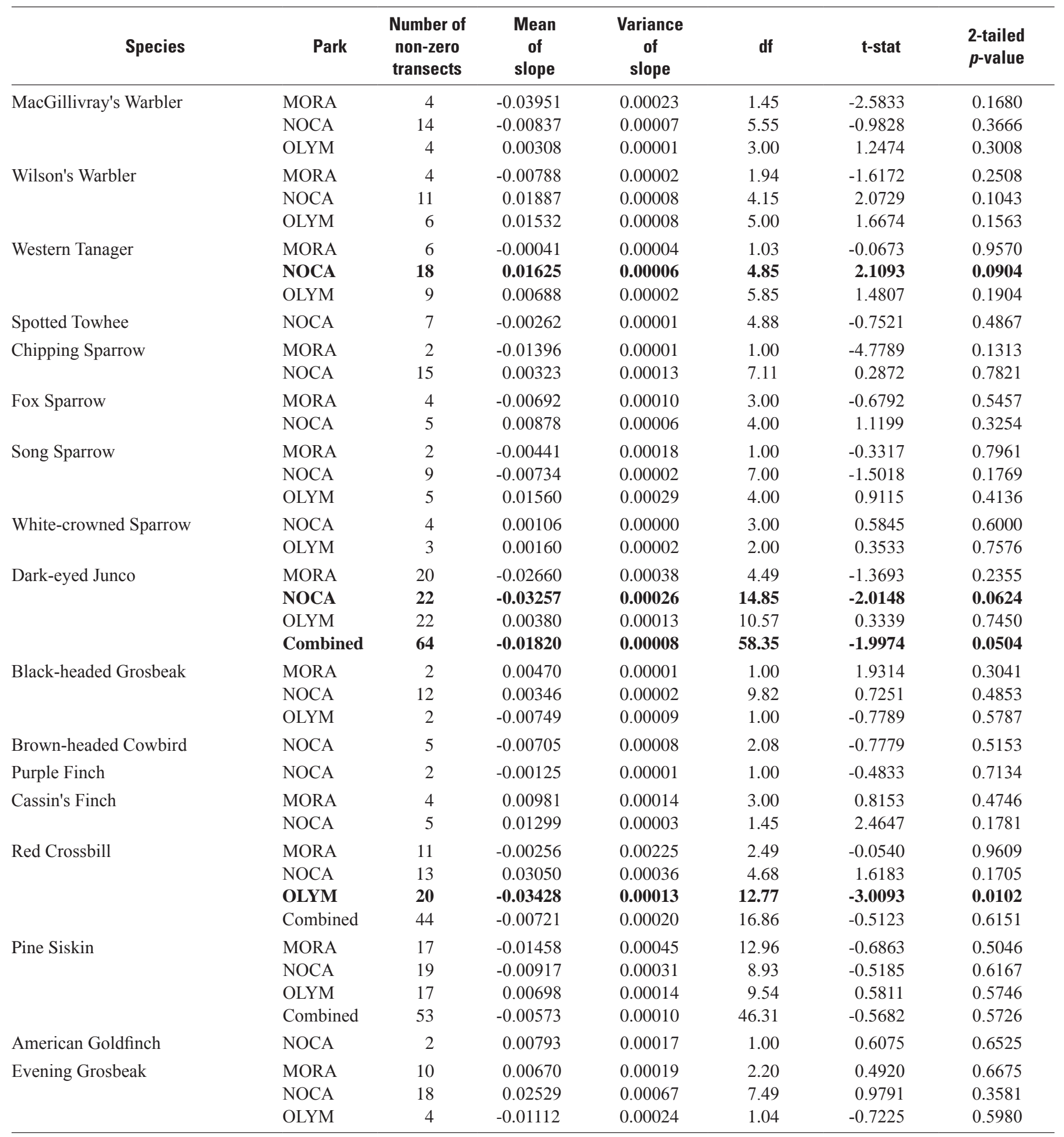


Red-breasted Sapsucker

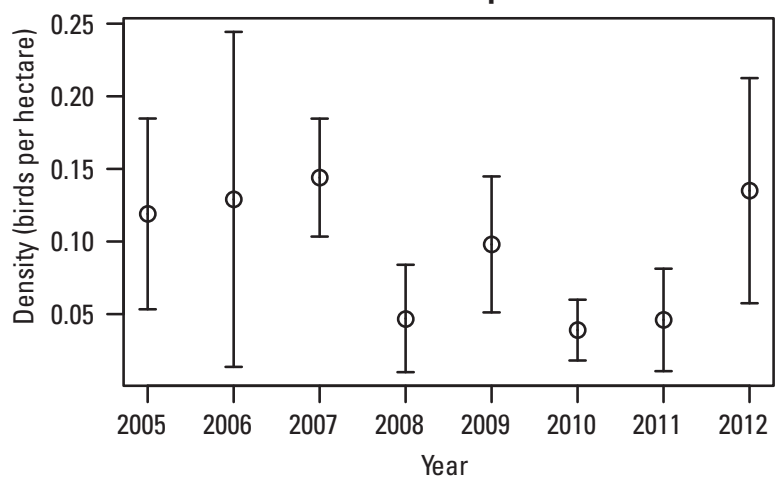

Swainson's Thrush

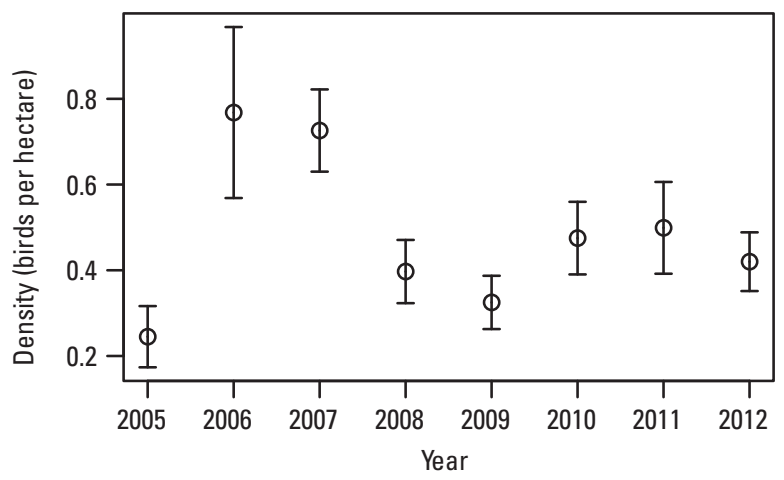

Dark-eyed Junco



Western Tanager

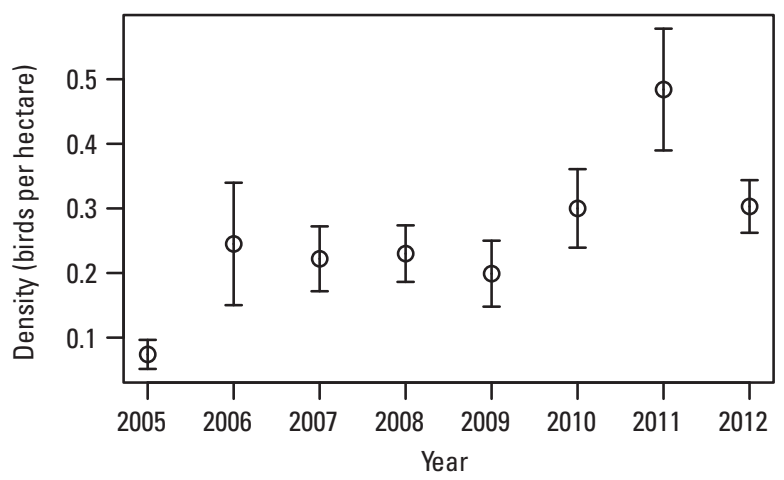

Golden-crowned Kinglet

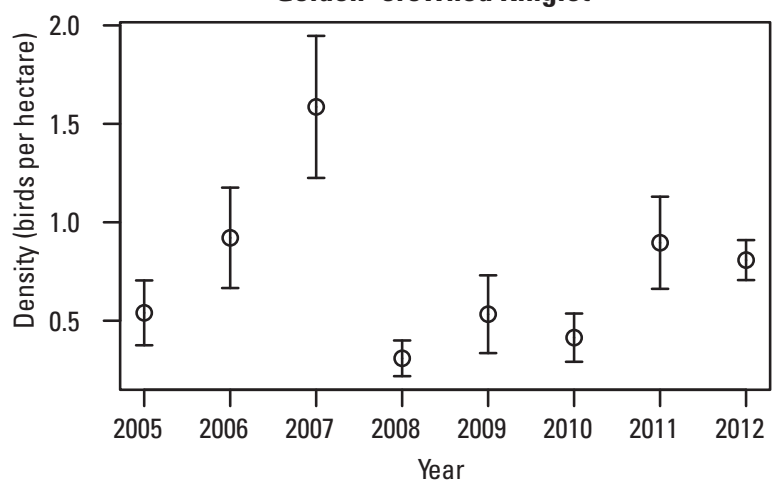

Hermit Thrush

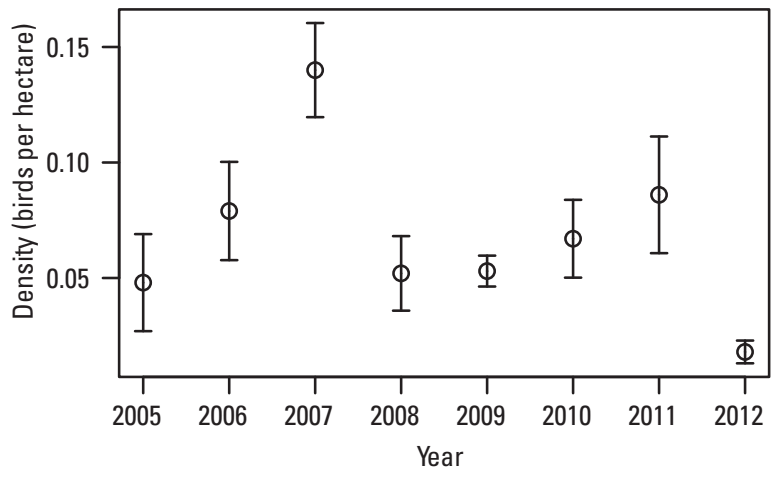

Gray Jay

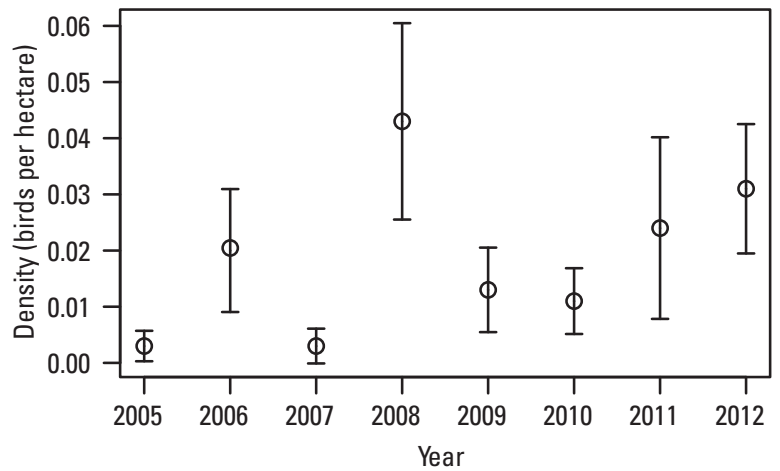

Figure 8. Annual mean point density estimates ( \pm standard error) based on data from all points (that is, not just from transects with detections) for seven species with significant trends at North Cascades National Park. Five species significantly decreased (Red-breasted Sapsucker, Golden-crowned Kinglet, Swainson's Thrush, Hermit Thrush, and Dark-eyed Junco) and two species significantly increased (Gray Jay and Western Tanager). 
Trends at OLYM were significant for 8 of 41 species (20 percent), 5 of which decreased (12 percent) and 3 of which increased (7 percent; table 3 ). Species with decreasing trends at OLYM included Band-tailed Pigeon (-0.2 percent per year), Vaux's Swift (-2.4 percent per year), Hairy Woodpecker (-1.0 percent per year), American Crow ( -0.2 percent per year), and Red Crossbill ( -3.4 percent per year). Species with increasing trends included Red-breasted Sapsucker $(+2.2$ percent per year $)$, Gray Jay $(+0.5$ percent per year), and American Robin ( +1.3 percent per year). Consistent with results from the other two parks, plots of annual density estimates showed high annual variation in density estimates (fig. 9).

Of 12 species for which we were able to estimate NCCNwide trends (for example, pooling data across all three large parks), 4 species had significant negative trends (table 4). These included Red-breasted Nuthatch, Pacific Wren, Goldencrowned Kinglet, and Dark-eyed Junco. For Red-breasted Nuthatch, the trend appeared to be driven largely by low densities in the last 2 years of the time series, 2011 and 2012 (fig. 10). For the remaining three species, the time series was characterized by increasing densities during the first 3 years and lower abundance thereafter.

\section{Bird Population Trends in Small Parks}

We estimated trends for 45 species at LEWI and for 43 species at SAJH. Trends for 2006-12 were statistically significant for 6 of 45 (13 percent) species at LEWI (table 5). Three of these species decreased-Band-tailed Pigeon, Northern Flicker, and Olive-sided Flycatcher; and three species increased-Brown Creeper, Golden-crowned Kinglet, and Song Sparrow. At SAJH, 3 (7 percent) of the 43 species (Cassin's Vireo, Swainson's Thrush, and Townsend's Warbler) significantly decreased and none significantly increased (table 6).

\section{Discussion}

\section{Avian Population Trends}

In the first years of monitoring landbird populations in the NCCN, we detected several incipient trends in avian density. Our analyses revealed significant trends for multiple species at each of the parks. Most of the significant $(P<0.10)$ trends in individual species were negative in direction (12 of 17 significant trends at large parks, all 4 significant trends in the combined large-park analysis, and 6 of 9 trends at small parks).
These preliminary indications of change, however, need to be interpreted with utmost caution at this early stage of the monitoring program. First, our analysis, based on data from 2005 to 2012, represents a fairly short-time span for this longterm monitoring project. The first 2 years of the time series (2005 and 2006) were implemented as part of a limited pilot study that included only the annual panel of transects. The subsequent 6 years (2007-12) represent just a single cycle through all five alternating panels, and repeat sampling of only one alternating panel. With such few years and repeat visits represented, random variability, particularly in the early or lateyears of the series, may have strong stochastic effects of the estimated rates of change. Secondly, with trends across so many species-park combinations being tested independently, we are likely to obtain some statistically significant trends in instances where changes are not truly biologically significant, simply because of Type I error. In consideration of these constraints, it may be prudent, therefore, to focus attention on species with significant trends in the same direction in multiple parks or trends that are significant at the multi-park level, and view trends that are apparent in only one park as provisional.

At this relatively early juncture, the pervasive pattern of large inter-annual variation in the density estimates for individual species is noteworthy (appendix 3). Even among the relatively few species with statistically significant trends, annual density estimates often fluctuated greatly between years, with estimates occasionally changing by 50 percent or more in consecutive years (igs. 7-10).

Annual weather variation can drive fluctuations in populations of small birds (Crick, 1999), and this may be particularly true in montane environments where conditions related to snowpack can vary so greatly from year to year. Elsewhere in the montane west it has been demonstrated that winters with heavy snow accumulation may be associated with reduced breeding bird abundance in subalpine and upper montane forests (Raphael and White, 1984; Hejl and others, 1988; DeSante, 1990). In addition, late snowpack or late-season storms can delay initiation of breeding, resulting in fewer nesting attempts, and decreased overall reproductive success in these high-elevation habitats (Hahn and others, 2004; Pereyra, 2011; Mathewson and others, 2012). The persistence of spring snowpack (Smith and Anderson, 1985) or the incidence of late-spring storms (Whitmore and others, 1977; Morton, 2002) also may affect bird populations at mid elevations. In years with greater spring snowpack, there may be less snow-free substrate suitable for nests (for ground- or shrub-nesting species) and less plant material available with which to construct or line nests early in the season, factors that could delay nest-building or egg-laying (Smith and Andersen, 1985; Pereyra, 2011) and result in smaller clutches, fewer nesting attempts, or lower nest success (Verhulst and Nilsson, 2008; Pereyra, 2011). 
Band-tailed Pigeon

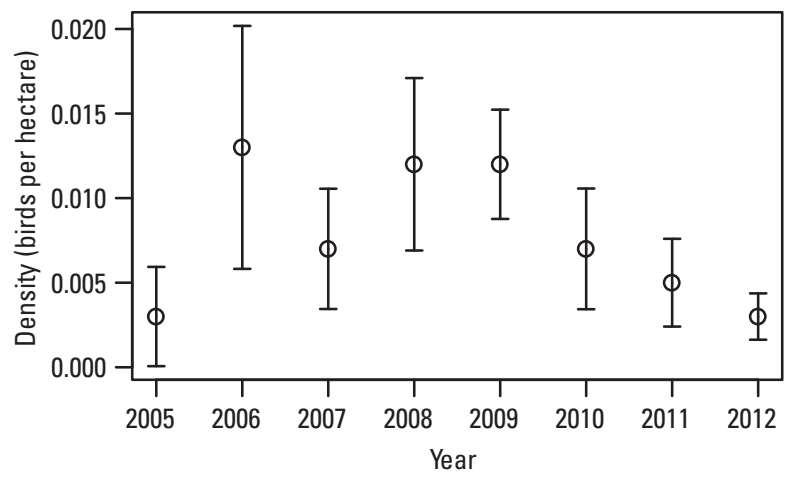

Hairy Woodpecker

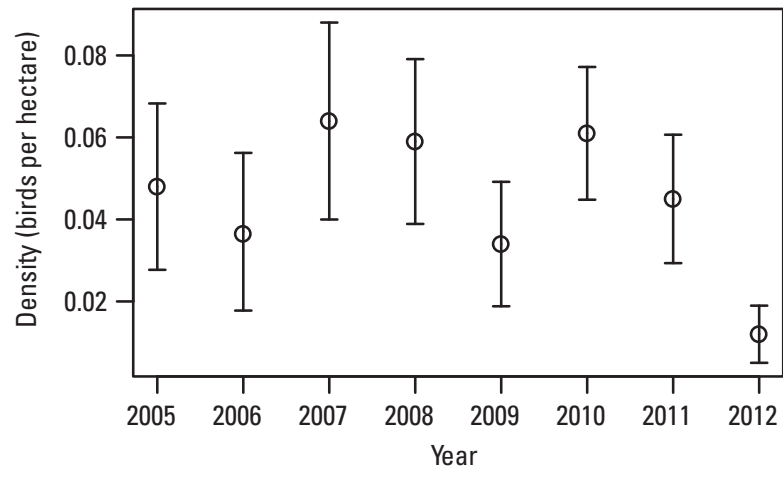

Red Crossbill

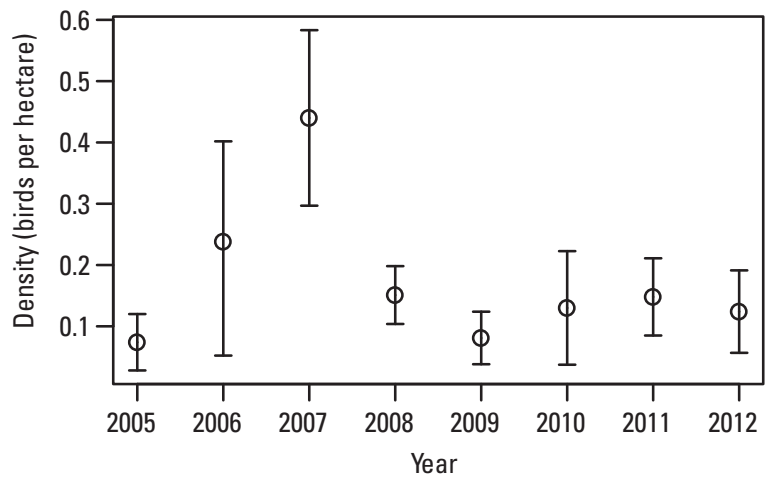

Gray Jay

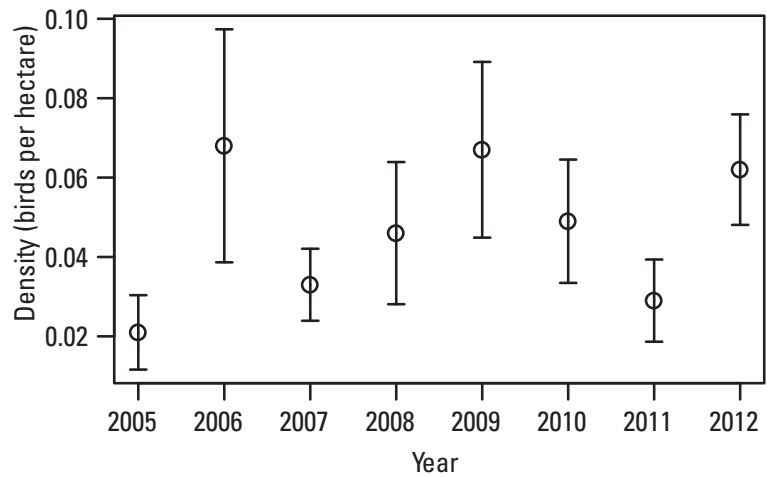

Vaux's Swift

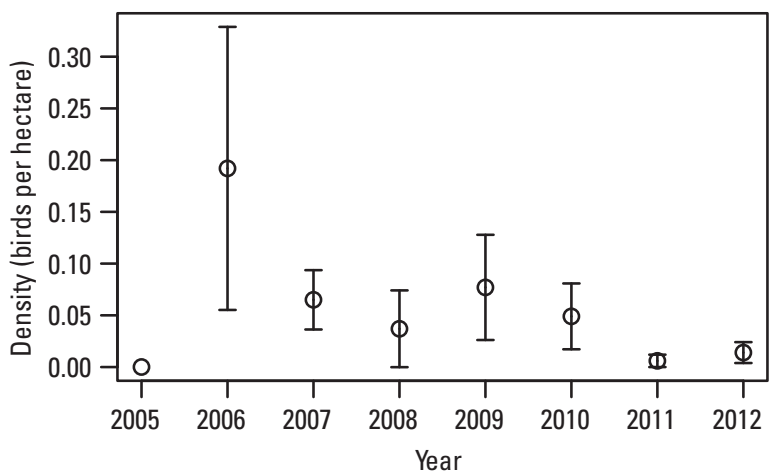

American Crow

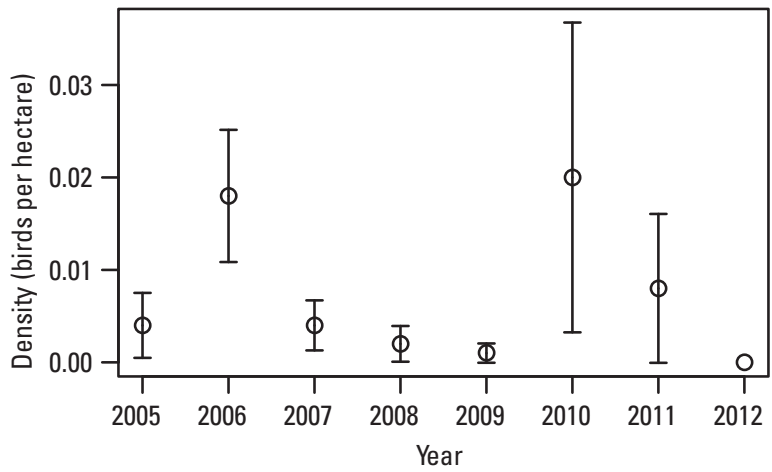

Red-breasted Sapsucker

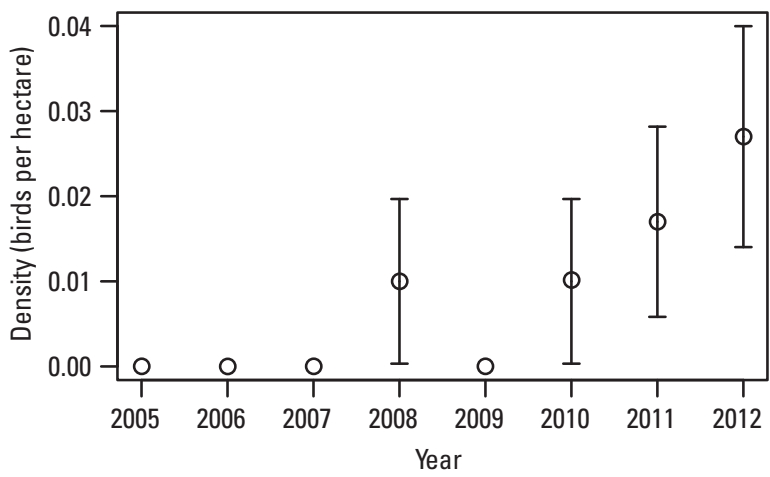

American Robin

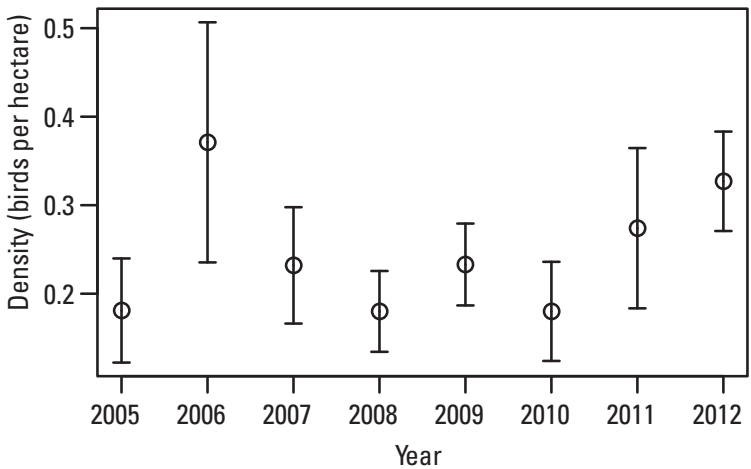

Figure 9. Annual mean point density estimates ( \pm standard error) based on data from all points (that is, not just from transects with detections) for eight species with significant trends at Olympic National Park. Five species significantly decreased (Band-tailed Pigeon, Vaux's Swift, Hairy Woodpecker, American Crow, and Red Crossbill) and three species significantly increased (Red-breasted Sapsucker, Gray Jay, and American Robin). 
Red-breasted Nuthatch



Golden-crowned Kinglet

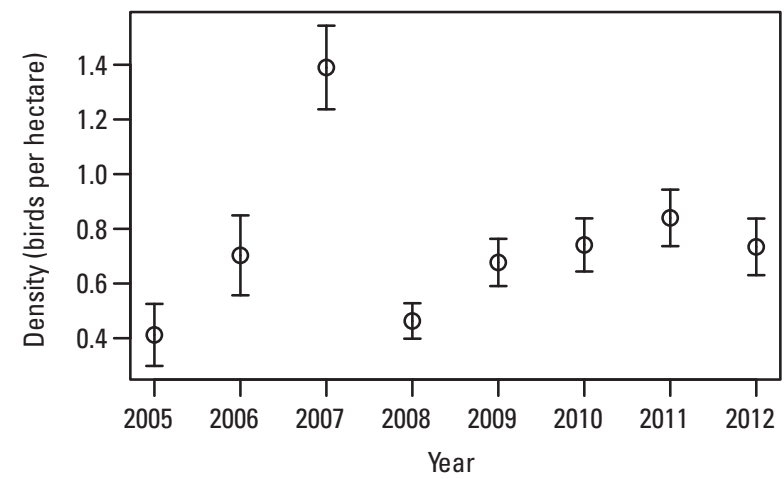

Pacific Wren

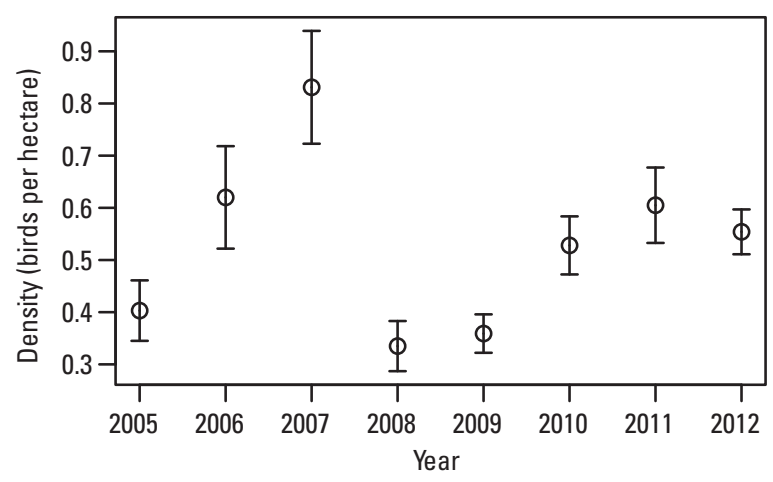

Dark-eyed Junco

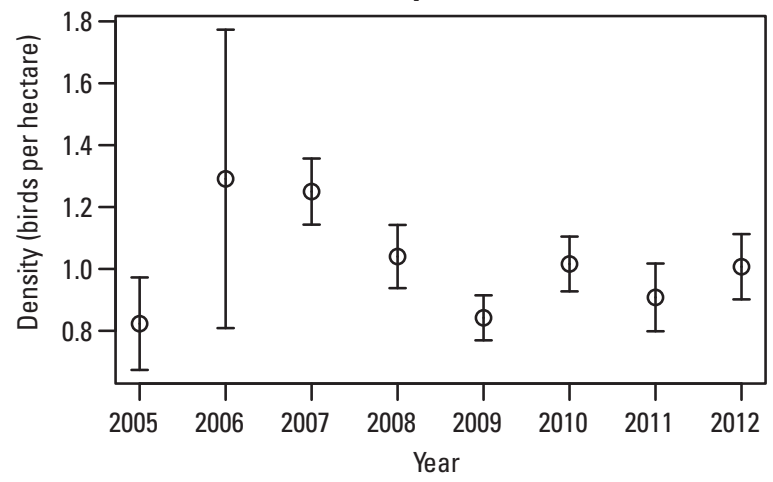

Figure 10. Annual mean point density estimates ( \pm standard error) based on data from all points (that is, not just from transects with detections) for four species with significant trends across the three large wilderness parks of the North Coast and Cascades Network. Note that combined-park trends could only be calculated for 12 species that were detected in all elevation strata at all parks.

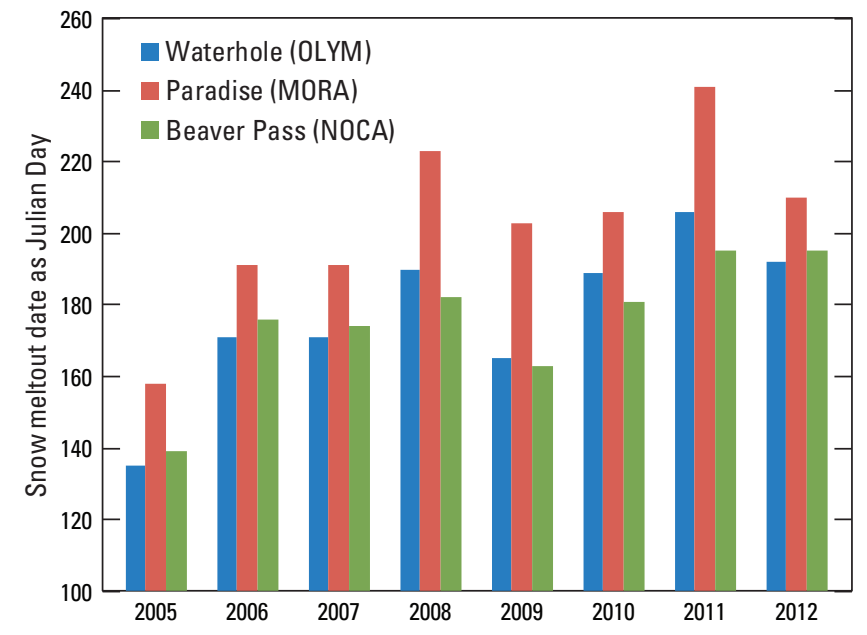

Figure 11. Annual snow meltout date (defined as ground surface albedo dropping below 30 percent) (Natural Resources Conservation Service, 2014) reported for individual snow telemetery ('SNOTEL') sites in each of the three large parks. 
Table 5. Trends for Lewis and Clark National Historical Park sampled biennially.

[Trends are slope estimates from a linear regression of log+1-transformed mean point-level density estimates as a function of year and can be interpreted as annual proportional changes. Species names are presented in standard taxonomic order (Chesser and others, 2013). Significant slopes $(P<0.10)$ are shown in bold]

\begin{tabular}{|c|c|c|c|c|c|}
\hline \multirow[b]{2}{*}{ Species } & \multicolumn{5}{|c|}{ Lewis and Clark National Historical Park (sampled in 2006, 2008, 2010, 2012) } \\
\hline & $\begin{array}{l}\text { Mean number } \\
\text { of points }\end{array}$ & $\begin{array}{c}\text { Mean density } \\
\text { (birds per hectare) }\end{array}$ & Trend & $\begin{array}{l}\text { Standard } \\
\text { error }\end{array}$ & Slope (P) \\
\hline Rufous Hummingbird & 5.50 & 3.310 & -0.345 & 0.510 & 0.568 \\
\hline Red-breasted Sapsucker & 0.25 & 0.005 & -0.003 & 0.002 & 0.225 \\
\hline Hairy Woodpecker & 1.50 & 0.020 & 0.007 & 0.004 & 0.266 \\
\hline Pileated Woodpecker & 1.50 & 0.003 & 0.000 & 0.001 & 0.612 \\
\hline Olive-sided Flycatcher & 10.75 & 0.038 & -0.006 & 0.000 & 0.003 \\
\hline Western Wood-Pewee & 2.25 & 0.010 & -0.004 & 0.001 & 0.105 \\
\hline Pacific-slope Flycatcher & 38.75 & 0.826 & 0.028 & 0.079 & 0.757 \\
\hline Cassin's Vireo & 0.25 & 0.003 & 0.001 & 0.001 & 0.742 \\
\hline Warbling Vireo & 7.75 & 0.076 & -0.016 & 0.009 & 0.204 \\
\hline Red-breasted Nuthatch & 5.25 & 0.041 & 0.003 & 0.004 & 0.552 \\
\hline Brown Creeper & 5.50 & 0.163 & 0.041 & 0.012 & 0.072 \\
\hline Pacific Wren & 43.00 & 0.867 & 0.024 & 0.105 & 0.841 \\
\hline Marsh Wren & 9.25 & 0.495 & 0.021 & 0.017 & 0.352 \\
\hline Golden-crowned Kinglet & 20.25 & 0.923 & 0.205 & 0.059 & 0.074 \\
\hline Swainson's Thrush & 54.25 & 0.895 & -0.011 & 0.067 & 0.884 \\
\hline American Robin & 31.00 & 0.553 & -0.007 & 0.012 & 0.631 \\
\hline Varied Thrush & 2.00 & 0.007 & 0.000 & 0.001 & 0.777 \\
\hline Orange-crowned Warbler & 14.75 & 0.236 & 0.008 & 0.010 & 0.521 \\
\hline Yellow Warbler & 7.00 & 0.140 & 0.006 & 0.016 & 0.763 \\
\hline Yellow-rumped Warbler & 0.75 & 0.010 & -0.001 & 0.002 & 0.560 \\
\hline Spotted Towhee & 3.25 & 0.030 & 0.005 & 0.002 & 0.115 \\
\hline Savannah Sparrow & 2.00 & 0.032 & -0.002 & 0.005 & 0.711 \\
\hline Song Sparrow & 28.25 & 0.503 & 0.063 & 0.015 & 0.051 \\
\hline White-crowned Sparrow & 11.75 & 0.069 & 0.002 & 0.002 & 0.479 \\
\hline Dark-eyed Junco & 12.00 & 0.439 & 0.014 & 0.068 & 0.850 \\
\hline Black-headed Grosbeak & 17.25 & 0.144 & 0.017 & 0.011 & 0.268 \\
\hline Red-winged Blackbird & 9.25 & 0.061 & 0.006 & 0.005 & 0.359 \\
\hline Brown-headed Cowbird & 12.25 & 0.223 & 0.027 & 0.013 & 0.180 \\
\hline Purple Finch & 16.75 & 0.107 & -0.004 & 0.005 & 0.531 \\
\hline Red Crossbill & 0.75 & 0.009 & -0.004 & 0.002 & 0.283 \\
\hline Pine Siskin & 0.25 & 0.003 & 0.001 & 0.001 & 0.742 \\
\hline American Goldfinch & 9.75 & 0.199 & -0.002 & 0.016 & 0.927 \\
\hline Evening Grosbeak & 0.50 & 0.053 & 0.032 & 0.018 & 0.225 \\
\hline
\end{tabular}


Table 6. Trends for San Juan Island National Historical Park sampled biennially.

[Trends are slope estimates from a linear regression of log+1-transformed mean point-level density estimates as a function of year and can be interpreted as annual proportional changes. Species names are presented in standard taxonomic order (Chesser and others, 2013). Significant slopes $(P<0.10)$ are shown in bold]

\begin{tabular}{|c|c|c|c|c|c|}
\hline \multirow[b]{2}{*}{ Species } & \multicolumn{5}{|c|}{ San Juan Island National Historical Park (sampled in 2007, 2009, 2011) } \\
\hline & $\begin{array}{l}\text { Mean number } \\
\text { of points }\end{array}$ & $\begin{array}{c}\text { Mean density } \\
\text { (birds per hectare) }\end{array}$ & Trend & $\begin{array}{l}\text { Standard } \\
\text { error }\end{array}$ & Slope $(P)$ \\
\hline Rufous Hummingbird & 7.00 & 5.842 & 0.797 & 0.460 & 0.333 \\
\hline Hairy Woodpecker & 1.33 & 0.022 & -0.002 & 0.001 & 0.333 \\
\hline Northern Flicker & 4.67 & 0.020 & 0.001 & 0.001 & 0.551 \\
\hline Hammond's Flycatcher & 0.33 & 0.007 & 0.000 & 0.006 & 1.000 \\
\hline Pacific-slope Flycatcher & 21.00 & 0.594 & -0.051 & 0.011 & 0.130 \\
\hline Cassin's Vireo & 2.67 & 0.036 & -0.017 & 0.002 & 0.073 \\
\hline Warbling Vireo & 8.00 & 0.129 & -0.029 & 0.010 & 0.211 \\
\hline Steller's Jay & 0.33 & 0.003 & 0.000 & 0.003 & 1.000 \\
\hline Brown Creeper & 4.67 & 0.161 & 0.034 & 0.020 & 0.333 \\
\hline House Wren & 19.67 & 0.305 & 0.059 & 0.033 & 0.324 \\
\hline Pacific Wren & 9.00 & 0.205 & -0.014 & 0.037 & 0.764 \\
\hline Golden-crowned Kinglet & 5.67 & 0.355 & 0.090 & 0.089 & 0.497 \\
\hline Swainson's Thrush & 19.33 & 0.275 & -0.056 & 0.005 & 0.055 \\
\hline American Robin & 38.33 & 1.147 & -0.053 & 0.157 & 0.793 \\
\hline Varied Thrush & 4.00 & 0.017 & 0.010 & 0.002 & 0.115 \\
\hline Orange-crowned Warbler & 23.00 & 0.442 & 0.011 & 0.007 & 0.333 \\
\hline Yellow Warbler & 1.00 & 0.014 & 0.003 & 0.006 & 0.672 \\
\hline Yellow-rumped Warbler & 5.00 & 0.057 & 0.019 & 0.008 & 0.247 \\
\hline Black-throated Gray Warbler & 6.00 & 0.114 & 0.000 & 0.020 & 1.000 \\
\hline Song Sparrow & 12.33 & 0.173 & 0.011 & 0.007 & 0.364 \\
\hline White-crowned Sparrow & 25.00 & 0.184 & 0.016 & 0.007 & 0.247 \\
\hline Dark-eyed Junco & 10.67 & 0.502 & 0.042 & 0.044 & 0.512 \\
\hline Black-headed Grosbeak & 3.33 & 0.036 & 0.005 & 0.003 & 0.333 \\
\hline Red-winged Blackbird & 8.67 & 0.156 & 0.014 & 0.034 & 0.755 \\
\hline Brown-headed Cowbird & 24.00 & 0.603 & 0.066 & 0.015 & 0.140 \\
\hline Purple Finch & 13.33 & 0.130 & 0.029 & 0.012 & 0.255 \\
\hline Red Crossbill & 0.67 & 0.009 & 0.000 & 0.004 & 1.000 \\
\hline Pine Siskin & 6.67 & 0.173 & -0.039 & 0.007 & 0.107 \\
\hline American Goldfinch & 25.67 & 0.724 & -0.057 & 0.073 & 0.582 \\
\hline
\end{tabular}


One example of a possible weather-related signal is already apparent in the data collected to date: the winter of 2007-08 was a La Niña year with heavy snowpack in the Pacific Northwest (fig. 11), perhaps explaining why breeding populations of so many species, particularly resident species, were sharply reduced in 2008. However, the same pattern of sharply reduced breeding populations was not evident in 2011, which was a year with even heavier snowpack in the region (fig. 11), indicating that other factors could be involved. Elucidating the effects of climate fluctuations or climate change on NCCN bird populations is a complicated task that needs to test effects of multiple climate variables and account for climatic variation across the diverse conditions within each park. Such analyses will be important components of future analyses of this growing dataset.

As described above, we view trends of individual avian species identified within a single park as provisional, and place more weight on trends identified in multiple parks or for the three large parks combined. Hence, species with the greatest evidence of change were the Red-breasted Nuthatch, Pacific Wren, Golden-crowned Kinglet and Dark-eyed Junco, all decreasing, and the Gray Jay, increasing.

Despite high annual variation and short time-series duration, trends in the large parks tended to agree with recent BBS trends estimated at larger spatial scales. For example, correlation between 2001 and 2011 BBS trends for Washington State (Sauer and others, 2012) and trends from each of the three large parks for species shared between the two surveys was positive in each case (correlation coefficients for the three large parks ranged from 0.20 to 0.28 with $P$-values from 0.07 to 0.15 ), and comparisons of average trends between the Washington BBS and each of the large parks showed no overall differences in percent annual change $(P$-values from paired t-tests [each species representing a pair] all $>0.4)$.

Despite overall similarities between regional trends and those at individual parks, it is worth noting that we detected trends in a variety of individual species-park combinations that were not evident in the regional BBS data. Furthermore, trends were not always consistent among parks. These findings may suggest evidence for regional-scale processes affecting bird populations as well as the need for continued monitoring at the scale of individual parks to understand factors affecting populations at finer spatial scales. However, an alternative interpretation is that they may provide a cautionary note about over-interpreting trend results from short-time series.

Although we were only able to estimate combinedpark trends for 12 species, 4 of the 12 showed significant population decreases. Here, too, there was general agreement between the NCCN 2005-12 trends and BBS trends. For example, three of these four species (Pacific Wren, Goldencrowned Kinglet, and Dark-eyed Junco) showed significant 2001-11 BBS decreases for Washington State and for the larger Northern Pacific Rainforest region, while the fourth species (Red-breasted Nuthatch) showed non-significant 2001-11 BBS decreases for these regions (Sauer and others, 2012). Pacific Wren, Golden-crowned Kinglet, and Darkeyed Junco also show longer term significant (1966-2012) BBS decreases at either (or both) the Washington or Northern Pacific Rainforest regions and at a continental scale (Sauer and others 2012, 2013). Although non-significant, the species with the largest-magnitude decreases for each of the three large parks of the NCCN was Rufous Hummingbird, a species that also shows severe short- and long-term regional decreases and is of overall high conservation concern (Partners in Flight, 2012; Watch List species; http://rmbo.org/pifassessment/ Database.aspx). Among species at the small parks with significant decreases, Olive-sided Flycatcher (decreasing at LEWI) is also a species showing severe regional decreases, although decreases in this species were not evident at the large parks. Both Rufous Hummingbird and Olive-sided Flycatcher were recently ranked as 'vulnerable' in a comprehensive analysis of the population status of North American bird species (American Bird Conservancy, 2012), and both species are Partners in Flight (PIF) U.S.-Canada Watch List species (Partners in Flight Science Committee, 2012). The only other PIF Watch List species observed during our monitoring was Cassin's Finch. We were able to estimate trends for this species in two of the large parks (MORA and NOCA); in both cases, we found no evidence of a significant trend.

Similarities in trends between the NCCN Landbird Monitoring Project and the BBS suggest that some factors driving trends are acting on populations at scales beyond the borders of individual parks. Climate change is an obvious example, and as more years of data are amassed, this project is likely to yield a rich source of information on the effects of annual weather variation on Pacific Northwest bird populations.

\section{Limitations of the Analytical Approach}

One of the primary goals of this first analysis of the NCCN landbird monitoring data was to implement and then evaluate the analytical methods prescribed in the protocol (Siegel and others, 2007). Our analytical approach to trend assessment for the large parks involved a multi-step process whereby (1) observations were corrected for imperfect detection based on distance-detectability functions, (2) mean transect-scale trends were estimated for each elevation stratum based on the corrected counts, and (3) trends were estimated at the park (or combined-park) scale based on the mean stratumlevel trends and the relative size of the sampling frame in each elevation stratum. This analytical approach was tightly integrated with the sampling design and aimed to provide a relatively simple and effective approach for assessing trends. Similarities in trends between the BBS and our study suggest this approach was effective and robust to potential limitations 
or problems involved with its implementation. Nevertheless, there are limitations to the approach, and subsequent to its development (initiated 10 years ago), a variety of advances in the field of modeling detectability and trend have become available and could improve future analyses of these data.

Here, we briefly discuss limitations of our analysis and offer suggestions for the future.

In regard to step 1 above, estimation of distancedetectability functions to correct raw count data (distance sampling) was a widely advocated means of correcting avian point count data for imperfect detection at the time the NCCN protocol was developed (Buckland and others, 2001, 2004). However, difficulties in meeting assumptions of the method in many avian point count surveys have since been widely acknowledged (for example, Alldredge and others, 2008; Johnson, 2008). The assumptions of perfect detectability at the point (that is, at distance $=0$ ) and no movement prior to detection may be particularly problematic. We found fewer detections than expected close to observers for many species (histogram peaks at distance $>0$ in appendix 2), suggesting that we failed to meet one or both of these assumptions for many species. This pattern might reflect birds moving from the point as observers approached (and not returning to their original locations), reduced singing rates of birds close to observers (McShea and Rappole, 1997), or a tendency for overestimation of distances for birds at or close to the point (for example, because of difficulties in localizing sounds directly overhead). Accurate assignment of distances may be a difficult assumption to meet in studies of singing birds, for a variety of reasons, including levels of ambient noise, and the direction the vocalizing bird is facing (Alldredge and others, 2007b, 2008). Finally, heterogeneity in detection probability among observers probably was important for most species in our study, yet models including observer effects could only be supported for species with the largest sample sizes, presumably because of the large numbers of parameters that need to be estimated in those models. Methods that allow observers to be modeled as random effects would alleviate this problem (for example, see Schmidt and others, 2013). Overall, we feel that our distance-detectability modeling efforts likely improved inferences about trend over analyses of raw count data, which would have ignored heterogeneity in detection probability. However, it is unclear the degree to which inability to meet assumptions and model all sources of heterogeneity in detection probability may have affected results of the detectability or trend analyses.

Other potential issues with the current trend analysis involve steps 2 and 3 above-the trend estimation methods implemented in the BirdTrend software. First, in step 2, uncertainty in slope estimation at the transect-scale (that is, residual variation in year-specific density estimates from the transect-level trend models) never explicitly enters into variance estimation at the stratum, park-wide, or combined-park scales. Thus, transect-level slopes are considered known quantities with equal weight for all transects. For some species-park combinations, differences in slope variances among transects were accounted for by assigning transects with different numbers of years of sampling to different variance groups; however, for many species there were not enough transects with detections in a park to separate annual and alternating panels into separate variance groups. A second potential problem with our trend estimation method relates to the fact that many bird species that were encountered in multiple elevation strata were rare in one or more of those strata. As long as individual birds of those species were encountered on at least two transects in each stratum where they were encountered, overall trends could be estimated; however, these trend estimates may not be the best metrics of trend because stratum-weighting of the overall trend is based on the sampling frame, not the potential distribution of the species. Ideally, the weighting of trends would reflect both the distribution of the species and the distribution of potential sampling transects in each elevation stratum. An additional consequence of rarity of a species in a particular elevation stratum is that when the species was only encountered on a single transect in that stratum, data had to be discarded because lone transects could not be combined across elevation strata because of different sampling weights among strata. This situation occurred in at least one park for more than one-half of the species we considered. Finally, in the current version of BirdTrend, combined-park trend estimates were only possible for species detected in all elevation strata of all parks. This precluded our ability to provide combinedpark trend estimates for more than one-half of the species found in all three parks.

\section{Suggestions for an Alternative Analytical Framework}

Despite these potential problems with the current analysis, the overall sampling design is strong and amenable to analysis by more recent methods that address these issues and provide a flexible framework for examining trends and other population parameters of interest, as well as testing hypotheses that relate the distribution and abundance of species to environmental covariates. These newer methods allow for modeling of various components of the detection process and analyzing observations (detection process), population state (occupancy, population size, density), and change (trend, local colonization and extinction rates, turnover) simultaneously (Nichols and others, 2009). Detection histories of individuals (informed mainly by the protocol with three intervals adopted in 2011) can be used within a time-of-detection closedpopulation framework to model population size (Alldredge and others, 2007a) or occupancy (Saracco and others, 2011) 
and detection probabilities. Changes in occupancy or population size also could be modeled with these detection histories based on methods developed for within-season repeated survey data (MacKenzie and others, 2003; Royle, 2004; Kéry and others, 2009). Even newer methods exploit open-population models that do not require multiple sampling intervals or within-season replication of counts (Dail and Madsen, 2011, 2013). All these techniques address a variety of limitations of the current analysis, including accounting for uncertainty in the detection and state processes simultaneously and at all spatial scales (from the individual transect to multiple parks), inclusion of random effects (for example, allowing for more efficient modeling of observer differences in detectability), allowing for the possibility of presence of birds at points with zero detections (that is, in the current analysis, zero counts are considered true zeros, while non-zero counts are corrected for imperfect detection), and providing a model-based, rather than a sampling-design based, approach to assessing trends. In addition, a modelbased approach would allow incorporation of all data from all elevation strata, provide a flexible framework for modeling detection probabilities and population parameters as functions of covariates (including detection probability-distance relationships), and (with a Bayesian Markov chain Monte Carlo implementation) allow summaries of trend (or other parameter) at multiple scales of interest. An example of such an analysis for a point-count based monitoring project (with replicated within-season counts) in a national park is provided by Schmidt and others (2013).

\section{Evaluating Operational Aspects of the North Coast and Cascades Network Landbird Monitoring Project}

Aside from the limitations of the current analytical framework described above, the implementation of the NCCN Landbird Monitoring Project has largely proceeded as intended and has been highly successful from an operational perspective. Despite occasional difficulties with transects being inaccessible because of late-lingering snowpack, washed out bridges, or other causes, the crew has successfully surveyed an average of 95 percent of the intended transects each year since monitoring began in 2005, with at least 90 percent of the intended transects surveyed in any particular year except for 2011 (table 2). During that year, a combination of heavy snowpack, frequent summer rain, and multiple crew members who were unable to pass the certification exam resulted in only 57 of the 68 intended transects ( 84 percent) being surveyed. Across all years of monitoring, the transect surveys that are missed most often tend to be those that require high-elevation travel to access or survey - generally because such travel is impeded by snow until late in the survey season during some years. Nevertheless, during 3 of the 8 years analyzed here (2005-12), 100 percent of the intended transects were surveyed, and in 2013, the crew again was able to survey all 68 transects.

\section{Sampling Frequency and Intensity}

The present multi-year analysis provides an opportunity to reflect on the project's sample design, particularly whether cost-saving reductions in sampling frequency or intensity might be warranted. In anticipation of possible budget shortfalls, several options for structuring such reductions have been considered in the past. Below we discuss briefly the tradeoffs involved with each option.

1. Discontinue monitoring in one or more of the three large parks. Elimination of a large park from the sampling frame would allow reduction of the seven-person field crew (comprised of a crew leader and six interns) by two interns. This would reduce costs associated with multiple project components, including data collection, dataquality assurance, and to a lesser degree, data analysis and reporting, but in all cases, the savings would be less than two-sevenths of the overall cost of the project component, because of efficiencies currently realized through an economy of scale. For example, the remaining four interns would still require supervision by a fulltime crew leader, who currently trains and supervises six interns. Additionally, extending inference to all three large parks-which vary considerably in their habitats and bird community composition-was a fundamental objective in the development of the NCCN Landbird Monitoring Project, and has frequently been identified as one of its important strengths.

2. Discontinue monitoring of the alternating panels of transects. Elimination of the alternative panels of transects would likely allow reduction of the crew by three interns and reduce costs associated with project components, including data collection, data-quality assurance, and to a lesser degree, data analysis and reporting. Cost savings would be greater than those realized by eliminating one large park, since three, rather than two, crew positions could be eliminated and the amount of data collected in the large parks would be reduced by one-half, rather than one-third. The primary disadvantage to this approach would be the loss of much of the program's ability to assess spatial heterogeneity in the dataset, because the alternating panels represent four-fifths of the total pool of transects. Even though the overall sampling frame would not be reduced if data collection were scaled back to just the annual panel of transects, the capacity of those transects to represent landbird dynamics across the extensive and diverse landscapes of the parks would be greatly reduced. 
3. Discontinuing monitoring of the annual panel of transects. Elimination of the annual panel of transects would reap similar cost-savings as elimination of the alternating panels of transects, but would largely preserve the program's ability to assess population dynamics across the diversity of the park landscapes, because four-fifths of the transects would be retained. The major disadvantage of this approach is that it would make it difficult, if not impossible, to separate spatial variation from temporal variation in bird densities, as our analysis reveals a high degree of annual variability in NCCN bird populations. In addition to complicating assessment of spatial and temporal variability, elimination of the annual panel would make it more difficult or impossible to assess and describe relationships between annual weather patterns and bird populations in the NCCN. In an era of increasing concern over the effects of climate change, sacrificing inference about the effects of weather (and by extension, climate) seems like a high price to pay.

4. Periodically skip a year of monitoring, perhaps coinciding with the production of each 5-year synthesis report. Periodically skipping a year of data collection may be the best way to reduce costs without undermining the integrity of the sample design or sacrificing important programmatic goals. Particularly if the skipped years coincide with the production of each 5-year report, the cost-savings in data collection, analysis, and reporting may free up needed funds for those reporting efforts. However, this approach also has drawbacks. Cost savings would only be approximately one-fifth of the current program costs (excluding production of the 5-year reports), and those savings would be realized only every 5 years, with no savings in the annual costs in the years when data collection is implemented. Additionally, skipping a year of data collection could result in difficulties restarting the efforts after the skipped year, particularly if staff members are reassigned to other duties during the interim and/or if field personnel who might otherwise return opt to leave the project permanently during the off year.

Considering the cost-cutting options together, we believe that option 4, periodically skipping a year of data collection, is the most tractable. However, we suggest that final decisions on the matter be delayed, as efforts are currently underway to develop and assess an alternative analytical framework for the NCCN Landbird Monitoring Program, and the increased analytical flexibility of the new approach may suggest other options for reducing data-collection effort and expenses.

\section{Safety}

Despite working largely off-trail, the NCCN landbird monitoring crew has never had a serious project-related injury. Nevertheless, we are continually reviewing and refining our safety procedures. Throughout the 8 years of our study, crews submitted a detailed itinerary for each trip to the park dispatch center and checked in twice daily over radios while in the field. More recently, the crew also started completing and submitting forms before each trip that identify the potential risk involved and indicate what is being done to mitigate those risks. In addition to these safety procedures, in 2013 the crew also attended a 2-day Operational Leadership Training and received training in ice axe usage and snow travel training, both provided by the NPS. This extra training was considered very helpful and will continue in future years.

\section{Successful Collaboration}

As a network-wide project implemented with a single field crew, the Landbird Monitoring Project requires close coordination among five national park units. Additionally, the project has been implemented every year through a cooperative agreement with a non-governmental organization, The Institute for Bird Populations, and also frequently relies on consultation with staff at USGS- Forest and Rangeland Ecosystem Science Center. By all accounts, this multi-party partnership has been highly successful, and has consistently produced data and reports on time and within budget constraints.

\section{Optimal Crew Size}

The project has been implemented over the years with a crew size ranging from six to eight surveyors, including one crew leader. Although the work nominally requires six people, a seven-person crew seems to be the optimal size, providing one fully trained backup person if needed in case of minor injuries (for example, sprained ankle) or another crew member's inability to pass the bird identification exam.

\section{Data-Sharing and Dissemination}

The project dataset has been requested by and provided to multiple independent researchers. Besides being posted online in the usual NPS locations, the project partners also have created a website (http://www.birdpop.net/ncen/) that describes the project and provides access to data and reports. The data and metadata represent a valuable asset, the value of which will only increase over time, especially given the context provided in the annual reports, field season crew lead summaries, and annual quality assurance documentation provided in the certification reports. 


\section{Training and Mentoring Young Biologists}

An ancillary benefit of having implemented landbird monitoring for NCCN has been that a cadre of five to seven field biologist interns has been trained in bird survey techniques and wilderness safety every year. Of the 36 interns who participated in monitoring for at least 1 year between 2005 and 2012, many have continued on to graduate studies and/or careers in the biological sciences or natural resource management.

\section{Conclusions}

The NCCN Landbird Monitoring Project is still in the early years of its implementation, with only one-third of its 204 transects having been eligible for re-survey prior to this analysis. The project is being implemented successfully at the operational level, and is already yielding preliminary findings that hint at the increasing value of the data and results in years to come as the remaining transects are re-visited and more years are added to the overall time series. Particular strengths of the project include its ability to monitor trends of dozens of species simultaneously, its broad area of inference across reasonably accessible areas (including much of the backcountry) of the large parks, and the integration of operations, analyses, and inference across multiple Network parks. The largest challenge now facing the project is the need to transition to a more modern, flexible analytical framework incorporating a model-based approach that will allow for modeling and analyzing observations (detection process), population state (occupancy, population size, density), and change (trend, survival, recruitment, turnover) simultaneously. A model-based approach should provide more flexibility to make adjustments for missed or reduced sampling effort, better ability to identify range or habitat shifts in response to climate change, and an enhanced capacity to test hypotheses about the effects of weather and habitat on temporal and spatial variation in bird populations.

\section{Acknowledgments}

We are grateful to the North Coast and Cascades Network and the Inventory and Monitoring Program of the National Park Service for funding this report and the annual data collection. We also thank Seattle City Light for providing additional funding for the inventory and initial project development; and the Skagit Environmental Endowment Commission for funding provided during data acquisition. We thank all of the 36 interns on the crew between 2005 and 2012 for their hard work and dedication to the project: J. Ajani, S. Alger, J. Baldwin, P. Burke, A. Byrd, M. Cejtin, K. Coffman,
G. Cotterill, B. Dudek, M.C. Fournier, A. Gilmore, C. Grattan, E. Huston, J. Krumlauf, K. Kuhlman, J. Love, S. Marek, M. McCloy, E. Mickelson, L. Mork, C. Mulvey, R. Niese, M. Ortega-Welch, H. Panci, S. Price, E. Reading, J. Shewan, E. Smith, K. Stassen, A. Tillinghast, A. Tyson, N. VanDyken, Z. Wallace, C. Waythomas, A. Wick, and D. Wolfson. We thank the entire NCCN Landbird Monitoring Group for their contributions toward developing the NCCN landbird monitoring protocol. We thank M. Reid, C. Clatterbuck, J. Weaver, J. Schaberl, S. Stonum, and C. Davis for providing project oversight at their respective parks; N. Antonova, K. Beirne, R. Hoffman, and D. Sweeny for GIS support and K. Beirne for providing maps for this report; $\mathrm{S}$. Gremel for varied logistical and field support; backcountry ranger and First Aid instructor C. Conley for volunteering his time to provide our crew with First Aid training; B. Baccus for compiling snow data for this report; Alice Shelly and Tamre Cardoso for invaluable help writing and testing code for the Bird Trend analysis; and the ESRI Conservation Program for software support provided to The Institute for Bird Populations. We thank Paul Geissler and an anonymous reviewer for helpful suggestions on a previous version of this report. This is Contribution No. 469 of The Institute for Bird Populations.

\section{References Cited}

Alldredge, M.W., Pacifici, K., Simons, T.R., and Pollock, K.H., 2008, A field evaluation of the effectiveness of distance sampling and double independent observers to estimate detection probability in aural avian point counts: Journal of Applied Ecology, v. 45, p. 1,349-1,356.

Alldredge, M.W., Pollock, K.H., Simons, T.R., Collazo, J.A., and Shriner, S.A., 2007a, Time-of-detection method for estimating abundance from point-count surveys: Auk, v. 124, p. 653.

Alldredge, M.W., Simons, T.R., Pollock, K.H., and Pacifici, K., 2007b, A field evaluation of the time-of-detection method to estimate population size and density for aural avian point counts: Avian Conservation and Ecology-Écologie et conservation des oiseaux, v. 2 no. 2, p. 13., http://www.ace-eco. org/vol2/iss2/art13/.

Altman, B., 2000, Conservation strategy for landbirds of the east slope of the Cascades-Version 1.0: Corvallis, Oreg., American Bird Conservancy, prepared for Oregon-Washington Partners in Flight.

Altman, B., 2005, Conservation priorities for landbirds of the Pacific Coast of Oregon and Washington, in Proceedings of the Third International Partners in Flight Symposium: General Technical Report PSW-GTR-191, Albany, California, USDA Forest Service, Pacific Southwest Research Station, p. 143-148. 
Altman, B., and Bart, J., 2001, Special species monitoring and assessment in Oregon and Washington-Landbird species not adequately monitored by the Breeding Bird Survey: Boring, Oreg., prepared for Oregon-Washington Partners in Flight by American Bird Conservancy and U.S. Geological Service.

American Bird Conservancy, 2012, List of the birds of the United States with conservation rankings: American Bird Conservancy, http://www.abcbirds.org/abcprograms/science/ conservationchecklist/index.html.

Andelman, S.J., and Stock, A., 1994a, Management, research, and monitoring priorities for the conservation of Neotropical migratory landbirds that breed in Oregon: Olympia, Wash., Washington Department of Natural Resources.

Andelman, S.J., and Stock, A., 1994b, Management, research, and monitoring priorities for the conservation of Neotropical migratory landbirds that breed in Washington: Olympia, Wash., Washington Department of Natural Resources.

Atkinson, S., and Sharpe, F.A., 1985, Wild plants of the San Juan Islands: Seattle, Wash., The Mountaineers/San Juan Preservation Trust.

Bolsinger, C.L., and Waddell, K.L., 1993, Area of old-growth forests in California, Oregon and Washington: Portland, Oreg., U.S. Department of Agriculture, U.S. Forest Service, Pacific Northwest Research Station, USDA Forest Service Resource Bulletin PNW-RB-197.

Breidt, F.J., and Fuller, W.A., 1999, Design of supplemented panel surveys with application to the national resources inventory: Journal of Agricultural, Biological, and Environmental Statistics, v. 4, p. 391-403.

Buckland, S.T., Anderson, D.R., Burnham, K.P., Borchers, D.L., and Laake, J.L., 2004, Advanced distance samplingEstimating abundance of biological populations: Oxford, United Kingdom, Oxford University Press.

Buckland, S.T., Anderson, D.R., Burnham, K.P., Laake, J.L., Borchers, D.L., and Thomas, L., 2001, Introduction to distance sampling: Oxford, United Kingdom, Oxford University Press.

Bunnell, F.L., Kremsater, L.L., and Wells, R.W., 1997, Likely consequences of forest management on terrestrial, forestdwelling vertebrates in Oregon-Report M-7 of the Centre for Applied Conservation Biology: Vancouver, Canada, University of British Columbia.

Burnham, K.P., and Anderson, D.R., 2002, Model selection and multi-model inference-A practical information theoretic approach (2nd ed.): New York, Springer-Verlag.

Chesser, T.R., Banks, R.C., Baarker, F.K., Cicer, C., Dunn, J.L., Kratter, A.W., Lovette, I.J., Rasmussen, P.C., Remsen, Jr., J.V., Rising, J.D., Stotz, D.F., and Winker, K., 2013, Fifty-fourth supplement to the American Ornithologists' Union Checklist of North American Birds: Auk, v. 130, p. 558-571.
Coonan, T.J., Austin, G., and Dye, L., 2001, Landbird monitoring 1995-2000 annual report: Ventura, Calif., Channel Islands National Park Technical Report 2001-03.

Crick, H.Q.P, 1999, Small bird population changes, in Cannell, M.G.R., Palutikof, J.P., and Sparks, T.H., eds., Indicators of climate change in the UK: London, United Kingdom, Climatic Research Unit and the Centre for Ecology and Hydrology.

Dail, D., and Madsen, M., 2011, Models for estimating abundance from repeated counts of an open metapopulation: Biometrics, v. 67, p. $577-587$.

Dail, D., and Madsen, M., 2013, Estimating open population site occupancy from presence-Absence data lacking the robust design: Biometrics, v. 69, p. 146-156.

DeSante, D.F., 1990, The role of recruitment in the dynamics of a Sierran subalpine bird community: American Naturalist, v. 136, p. $429-455$.

Fancy, S.G, 1997, A new approach for analyzing bird densities from variable circular-plot counts: Pacific Science, v. 51, p. 107-114.

Field, S.A., Tyre, A.J., Jonzén, N., Rhodes, J.R., and Possingham, H.P., 2004, Minimizing the cost of environmental management decisions by optimizing statistical thresholds: Ecology Letters, v. 7, p. 669-675.

Gardali T., Seavy, N.E., DiGaudio, R.T., and Comrack, L.A., 2012, A climate change vulnerability assessment of California's at-risk birds: PLoS ONE, v. 7 no. 3, e29507, doi:10.1371/ journal.pone.0029507.

Hagar, J.C., McComb, W.C., and Chambers, C.C., 1995, Effects of forest practices on wildlife, in Beschta, R.P., and others (eds.), Cumulative effects of forest practices in OregonLiterature and synthesis: Corvallis, Oregon State University.

Hahn, T.P., Sockman, K.W., Breuner, C.W., and Morton, M.L., 2004, Facultative altitudinal movements by Mountain WhiteCrowned Sparrows (Zonotrichia leucophrys oriantha) in the Sierra Nevada: Auk, v. 121, p. 1,269-1,281.

Hejl, S.J., Verner, J., and Balda, R.P., 1988, Weather and bird populations in true fire forests of the Sierra Nevada, California: Condor, v. 90, p. 561-574.

Jenkins, K., Beirne, K., and Seaman, D.E., 2000, Inventory and monitoring of breeding land birds in Olympic National ParkPreliminary results - 1999 annual report: U.S. Geological Survey.

Johnson, D.H., 2008, In defense of indices - The case of bird surveys: Journal of Wildlife Management, v. 72, p. 857-868.

Kéry, M., Dorazio, R.M., Soldaat, L., Van Strien, A., Zuiderwijk, A., and Royle, J.A., 2009, Trend estimation in populations with imperfect detection: Journal of Applied Ecology, v. 46, p. $1,163-1,172$. 
Lewis, M.G., and Sharpe, F.A., 1987, Birding in the San Juan Islands: Seattle, Wash., The Mountaineers.

Linden, D.W., and Roloff, G.J., 2013, Retained structures and bird communities in clearcut forests of the Pacific Northwest, USA: Forest Ecology and Management, v. 310, p. 1,045-1,056.

Linden, D.W., Roloff, G.J., and Kroll, A.J., 2012, Conserving avian richness through structure retention in managed forests of the Pacific Northwest, USA: Forest Ecology and Management, v. 284 , p. $174-184$.

MacKenzie, D.I., Nichols, J.D., Hines, J.E., Knutson, M.G., and Franklin, A.B., 2003, Estimating site occupancy, colonization and local extinction probabilities when a species is not detected with certainty: Ecology, v. 84, p. 2,200-2,207.

Mathewson, H.A., Morrison, M.L., Loffland, H.L., and Brussard, P., 2012, Ecology of Willow Flycatchers (Empidonax trailii) in the Sierra Nevada, California-Effects of meadow characteristics and weather on demographics: Ornithological Monographs, v. 75, p. 1-32.

McDonald, T.L., 2003, Review of environmental monitoring methods-Survey designs: Environmental Monitoring and Assessment, v. 85, p. 277-292.

McShea, W.J., and Rappole, J.H., 1997, Variable song rates in three species of passerines and implications for estimating bird populations: Journal of Field Ornithology, v. 68, p. 367-375.

Meslow, E.C., and Wight, H.M., 1975, Avifauna and succession in Douglas-fir forests of the Pacific Northwest, in Smith, D.R., ed., Proceedings of the symposium on management of forest and rangeland habitats for non-game birds: U.S. Department of Agriculture, Forest Service General Technical Report WO-1.

Miller, D.L., 2012, Distance-A simple way to fit detection functions to distance sampling data and calculate abundance/ density for biological populations: R Project, R package version 0.7.1., http://CRAN.R-project.org/package=Distance.

Morton, M.L., 2002, The Mountain White-crowned SparrowMigration and reproduction at high altitude: Studies in Avian Biology, v. 24, p. 1-36.

Natural Resources Conservation Service, 2014, Washington SNOTEL sites web site: U.S. Department of Agriculture, accessed February 6, 2014, at http://www.wcc.nrcs.usda.gov/ snotel/Washington/washington.html.

Nelson, J.T., and Fancy, S.G., 1999, A test of the variable circularplot method when exact density of a bird population was known: Pacific Conservation Biology, v. 5, p. 139-143.

Nichols, J.D., Thomas, L., and Conn, P.B., 2009, Inferences about landbird abundance from count data-Recent advances and future directions, in Thomson, D.L., Cooch, E.G., Conroy, M.J., eds., Modeling demographic processes in marked populations: New York, Springer, p. 201-235.
Partners in Flight Science Committee, 2012, Species assessment database, version 2012: Partners in Flight Science Committee, January 22, 2014, at http://rmbo.org/pifassessment.

Peitz, D.G., Fancy, S.G., Thomas, L.P., and Witcher, B., 2002, Bird monitoring protocol for Agate Fossil Beds National Monument, Nebraska and Tallgrass Prairie National Preserve, Kansas, Prairie Cluster Prototype Monitoring Program: U.S. National Park Service.

Pereyra, M.E., 2011, Effects of snow-related environmental variation on breeding schedules and productivity in a high altitude flycatcher (Empidonax oberholseri): Auk, v. 128, p. $746-758$.

R Development Core Team, 2012, R-A language and environment for statistical computing: Vienna, Austria, R Foundation for Statistical Computing, ISBN 3-900051-07-0, http://www.R-project.org/.

Raphael, M.G., and White, M., 1984, Use of snags by cavitynesting birds in the Sierra Nevada: Wildlife Monographs 86.

Reynolds, R.T., Scott, J.M., and Nussbaum, R.A., 1980, A variable circular-plot method for estimating bird number: Condor, v. 82, p. 309-313.

Rosenstock, S.S., Anderson, D.R., Giesen, K.M., Leukering, T., and Carter, M.F., 2002, Landbird counting techniquesCurrent practices and an alternative: Auk, v. 119, p. 46-53.

Royle, J.A., 2004, N-mixture models for estimating population size from spatially replicated counts: Biometrics, v. 60, p. 108-115.

Saab, V.A., and Rich, T.D., 1997, Large-scale conservation assessment for Neotropical migratory land birds in the interior Columbia River basin: General Technical Report PNWGTR-399, U.S. Department of Agriculture, Forest Service, Pacific Northwest Research Station, Portland, Oregon, 56 p.

Saracco, J.F., Siegel, R.B., and Wilkerson, B.L., 2011, Occupancy modeling of black-backed woodpeckers on burned Sierra Nevada forests: Ecosphere, v. 2, no. 3, doi:10.1890/ES1000132.1

Sauer, J.R., Hines, J.E., Fallon, K.L. Pardieck, D.J. Ziolkowski, Jr., and Link, W.A., 2012, The North American Breeding Bird Survey, Results and Analysis 1966-2011, Version 07.03.2013: USGS Patuxent Wildlife Research Center, Laurel, MD.

Sauer, J.R., Link, J.E., Fallon, Pardieck, K.L., and Ziolkowski, Jr., D.J., 2013, The North American Breeding Bird Survey 1966-2011 - Summary Analysis and Species Accounts: North American Fauna, v. 79, p. 1-32, doi:10.3996/nafa.79.0001.

Satterthwaite, F.E., 1946, An approximate distribution of estimates of variance components: Biometrics Bulletin 2, p. 110-114, doi:10.2307/3002019. 
Schmidt, J.H., McIntyre, C.L., and MacCluskie, M.C., 2013, Accounting for incomplete detection-What are we estimating and how might it affect long-term passerine monitoring programs?: Biological Conservation, v. 160, p. 130-139.

Sharp, B.E., 1996, Avian population trends in the Pacific Northwest: Bird Populations, v. 3, p. 26-45.

Siegel, R.B., Pyle, P., Thorne, J.H., Holguin, A.J., Howell, C.A., Stock, S., and Tingley, M., 2014, Vulnerability of birds to climate change in California's Sierra Nevada: Avian Conservation and Ecology, v. 9, no. 1, p. 7, http://www.aceeco.org/vol9/iss1/art7/.

Siegel, R.B., and Wilkerson, R.L., 2005, Sample designs for avian monitoring alternatives in Sierra Nevada Network national parks: Point Reyes Station, Calif., The Institute for Bird Populations, Report to the Sierra Nevada Network of the National Park Service.

Siegel, R.B., Wilkerson, R.L., and Goldin Rose, M., 2010, Bird monitoring protocol for national parks in the Sierra Nevada Network: Fort Collins, Colo., U.S. National Park Service, Natural Resource Report NPS/SIEN/NRR-2010/231.

Siegel, R.B., Wilkerson, R.L., and Hall, S., 2009a, Landbird inventory for Olympic National Park (2002-2003): Fort Collins, Colo., U.S. National Park Service, Natural Resource Technical Report NPS/NCCN/NRTR—2009/159.

Siegel, R.B., Wilkerson, R.L., Jenkins, K.J., Kuntz II, R.C., Boetsch, J.R., Schaberl, J.P., and Happe, P.J., 2007, Landbird monitoring protocol for national parks in the North Coast and Cascades Network: U.S. Geological Survey Techniques and Methods 2-A6, $208 \mathrm{p}$.

Siegel, R.B., Wilkerson, R.L., and Kuntz II, R.C., 2009c, Landbird inventory for Lewis and Clark National Historical Park (2006): Fort Collins, Colo., U.S. National Park Service, Natural Resource Technical Report NPS/NCCN/NRTR2009/166.

Siegel, R.B., Wilkerson, R.L., Kuntz II, R.C., and McLaughlin, J.F., 2009d, Landbird inventory for North Cascades National Park Complex (2001-2002): Fort Collins, Colo., U.S. National Park Service, Natural Resource Technical Report NPS/NCCN/ NRTR-2009/152.

Siegel, R.B., Wilkerson, R.L., Kuntz II, R.C., Saracco, J.F., and Holmgren, A.L., 2012, Elevation ranges of birds at Mount Rainier National Park, North Cascades National Park Complex, and Olympic National Park: Northwestern Naturalist, v. 93, p. 23-39, doi: 10.1898/11-08.1

Siegel, R.B., Wilkerson, R.L., Pedersen, H.K., and Kuntz II, R.C., 2009e, Landbird inventory of San Juan Island National Historical Park (2002): Fort Collins, Colo., U.S. National Park Service, Natural Resource Technical Report NPS/NCCN/ NRTR-2009/156.
Silsbee, G.G., and Peterson, D.L., 1991, Designing and implementing comprehensive long-term inventory and monitoring programs for National Park System lands: Denver, Colo., Natural Resources Report NPS/NRUW/NRR-91/04.

Simons, T.R., Rabenold, K.N., Buehler, D.A., Collazo, J.A., and Fransreb, K.E., 1999, The role of indicator speciesNeotropical migratory song birds in Peine, J.D., ed., Ecosystem Management for Sustainability—Principles and Practices Illustrated by a Regional Biosphere Reserve Cooperative: New York, Lewis Publishers, p. 187-208.

Smith, K.G., and Andersen, D.C., 1985, Snowpack and variation in reproductive ecology of a montane ground-nesting passerine, Junco hyemalis: Ornis Scandinavica, v. 16, p. 8-13.

Sokal, R.R., and Rohlf, F.J., 1995, Biometry-The Principles and Practice of Statistics in Biological Research)(3d ed.): New York, W.H. Freeman and Company.

Stevens Jr., D.L., and Olsen, A.R., 1999, Spatially restricted surveys over time for aquatic resources: Journal of Agricultural, Biological, and Environmental Statistics, v. 4, p. 415-428.

Stevens Jr., D. L., and Olsen, A.R., 2004, Spatially balanced sampling of natural resources: Journal of the American Statistical Association, v. 99, p. 262-278.

Stevens Jr., D.L., and Olsen, A.R., 2003, Variance estimation for spatially balanced samples of environmental resources: EnvironMetrics, v. 14, p. 593-610.

Thomas, L., Buckland, S.T., Rexstad, E.A., Laake, J.L., Strindberg, S., Hedley, S.L., Bishop, J.R.B., Marques, T.A., and Burnham, K.P., 2010, Distance software-Design and analysis of distance sampling surveys for estimating population size: Journal of Applied Ecology, v. 47, p. 5-14.

Urquhart, N.S., and Kincaid, T.M., 1999, Designs for detecting trend from repeated surveys of ecological resources: Journal of Agricultural, Biological, and Environmental Statistics, v. 4, p. 404-414.

Urquhart, N.S., Paulsen, S.G., and Larsen, D.P., 1998, Monitoring for policy-relevant regional trends over time: Ecological Applications, v. 8, p. 246-257.

Verhulst, S., and Nilsson, J.-Å., 2008, The timing of birds' breeding seasons-A review of experiments that manipulated timing of breeding - Philosophical Transactions of the Royal Society B: Biological Sciences, v. 363, p. 399-410.

Whitmore, R.C., Mosher, J.A., and Frost, H.H., 1977, Spring migrant mortality during unseasonable weather: Auk, v. 94, p. 778-781.

Yegorova, S., Betts, M.G., and Puettmann, K.J., 2013, Birdvegetation associations in thinned and unthinned young Douglas-fir forests 10 years after thinning: Forest Ecology and Management, v. 310, p. 1,057-1,070. 


\section{Appendix 1. Common and Scientific Names of Species Used in Trend Analysis}

[Species names are presented in standard taxonomic order (Chesser and others, 2013)]

\begin{tabular}{|c|c|c|c|}
\hline Species & Scientific name & Species & Scientific name \\
\hline Sooty Grouse & Dendragapus fuliginosus & American Robin & Turdus migratorius \\
\hline Band-tailed Pigeon & Patagioenas fasciata & Varied Thrush & Ixoreus naevius \\
\hline Rufous Hummingbird & Selasphorus rufus & Orange-crowned Warbler & Oreothlypis celata \\
\hline Red-breasted Sapsucker & Sphyrapicus ruber & Nashville Warbler & Oreothlypis ruficapilla \\
\hline Northern Flicker & Colaptes auratus & Yellow-rumped Warbler & Setophaga coronata \\
\hline Pileated Woodpecker & Dryocopus pileatus & Black-throated Gray Warbler & Setophaga nigrescens \\
\hline Olive-sided Flycatcher & Contopus cooperi & Townsend's Warbler & Setophaga townsendi \\
\hline Western Wood-Pewee & Contopus sordidulus & Hermit Warbler & Setophaga occidentalis \\
\hline Warbling Vireo & Vireo gilvus & Western Tanager & Piranga ludoviciana \\
\hline Gray Jay & Perisoreus canadensis & Spotted Towhee & Pipilo maculatus \\
\hline Steller's Jay & Cyanocitta stelleri & Chipping Sparrow & Spizella passerina \\
\hline Clark's Nutcracker & Nucifraga columbiana & Savannah Sparrow & Passerculus sandwichensis \\
\hline American Crow & Corvus brachyrhynchos & Fox Sparrow & Passerella iliaca \\
\hline Common Raven & Corvus corax & Song Sparrow & Melospiza melodia \\
\hline Mountain Chickadee & Poecile gambeli & White-crowned Sparrow & Zonotrichia leucophrys \\
\hline Chestnut-backed Chickadee & Poecile rufescens & Dark-eyed Junco & Junco hyemalis \\
\hline Ruby-crowned Kinglet & Regulus calendula & Pine Siskin & Spinus pinus \\
\hline Townsend's Solitaire & Myadestes townsendi & American Goldfinch & Spinus tristis \\
\hline Swainson's Thrush & Catharus ustulatus & Evening Grosbeak & Coccothraustes vespertinus \\
\hline Hermit Thrush & Catharus guttatus & & \\
\hline
\end{tabular}




\section{Appendix 2. Distance-Detection Histograms and Predicted Detection Probabilities}

The appendix contains histograms of distance-detection data and predicted detection probabilities used to correct count data for imperfect detection for 61 bird species with at least 75 detections at point count stations in national parks of the North Coast and Cascades Network from 2005 to 2012. Appendix 2 in .PDF format can be downloaded from http://pubs.usgs. gov/of/2014/1202/.

\section{Appendix 3. Annual Density Estimates}

The appendix contains graphs showing annual mean point density estimates from 2005 to 2012 for 56 bird species with sufficient data to estimate trends in at least one of three large national parks of the North Coast and Cascades Network. Estimates are also shown for the three national parks combined. Appendix 3 in .PDF format can be downloaded from http://pubs.usgs.gov/ of/2014/1202/. 
Publishing support provided by the U.S. Geological Survey Science Publishing Network, Tacoma Publishing Service Center

For more information concerning the research in this report, contact the Director, Forest and Rangeland Ecosystem Science Center U.S. Geological Survey 9777 NW 9th St., Suite 400

Corvallis, Oregon 97330

http://fresc.usgs.gov 
